This document is the accepted manuscript version of the following article:

Kubilay, A., Carmeliet, J., \& Derome, D. (2017). Computational fluid dynamics simulations of wind-driven rain on a mid-rise residential building with various types of facade details. Journal of Building Performance Simulation, 10(2), 125-143.

https://doi .org/10.1080/19401493.2016.1152304

\title{
CFD simulations of wind-driven rain on a mid-rise residential building with various types of facade details
}

\author{
A. Kubilay ${ }^{a, b, *}$, J. Carmeliet ${ }^{a, b}$, D. Derome ${ }^{a, b}$ \\ ${ }^{a}$ Chair of Building Physics, Swiss Federal Institute of Technology ETHZ, Zurich, Switzerland \\ ${ }^{b}$ Laboratory for Multiscale Studies in Building Physics, Swiss Federal Laboratories for Materials Science and Technology \\ (Empa), Dübendorf, Switzerland \\ * Corresponding author: Aytaç Kubilay, Laboratory for Multiscale Studies in Building Physics, Swiss Federal Laboratories \\ for Materials Science and Technology (Empa), Überlandstrasse 129, CH-8600, Dübendorf, Switzerland. Tel.: +41 58765 \\ 4276; E-mail address: aytac.kubilay@empa.ch
}

\begin{abstract}
Numerical studies of wind-driven rain (WDR), reporting detailed analysis of rain exposure on building facades, focus mainly on simplified building facades. However, small-scale facade details have large impact on the rain exposure of a building, redistributing WDR locally. The present study reports results of computational fluid dynamics (CFD) simulations with Eulerian multiphase (EM) model for WDR on a stand-alone mid-rise residential building. The influence of facade details, namely roof overhangs, balconies and window sills, is analyzed. It is shown that even a very small surface detail, such as a window sill with a size of $0.10 \mathrm{~m}$ can decrease catch ratio by up to $37 \%$ and droplet impact speed by up to $40 \%$. Numerical simulations also show the practicality of the EM model for detailed analysis of WDR intensity on a complex building and its ability to be used as a design tool.
\end{abstract}

Keywords: Wind-driven rain, Computational fluid dynamics (CFD), Eulerian multiphase model, Facade details, Roof overhang, Balconies

\section{Introduction}

Wind-driven rain (WDR) is the type of rain which has a horizontal velocity vector due to the effect of wind flow occurring at the same time. WDR is one of the most important moisture sources that influence the hygrothermal performance and the durability of building facades. Rain can lead to film runoff on building facades, which may cause leakage, or be absorbed, which may transport moisture to internal layers of the facade. Through such mechanisms, several undesired phenomena in building physics can occur, such as frost damage at exterior wall surfaces (Van Balen 1996; Franke et al. 1998), erosion of building materials (Tang et al. 2004; Erkal et al. 2012), moisture induced salt migration (Charola and Lazzarini 1986; Franke et al. 1998), discoloration by efflorescence (Franke et al. 1998), surface soiling (Davidson et al. 2000; Etyemezian et al. 2000) and biological growth such as algae growth on the exterior (Barberousse et al. 2007) and mold growth at the interior wall surfaces (Abuku et al. 2009c), etc.

Blocken and Carmeliet (2010) and Blocken (2014) provide extensive reviews of different methods to estimate WDR intensity. Computational fluid dynamics (CFD) simulations of WDR have the advantage of providing detailed spatial and temporal distributions of WDR intensity on complex building geometries. A steady-state numerical simulation technique for WDR was developed by Choi $(1991,1993,1994,2002)$ by combining the Reynolds-averaged Navier-Stokes (RANS) 
equations and a Lagrangian particle tracking (LPT) model. Blocken and Carmeliet (2002) extended Choi's simulation technique by adding the temporal component, allowing the determination of both the spatial and temporal distribution of WDR for transient rain events. LPT is the most commonly used method to estimate WDR intensity in the literature (Hangan 1999; Etyemezian et al. 2000; Blocken and Carmeliet 2002; van Mook 2002; Tang and Davidson 2004; Blocken and Carmeliet 2006a, 2007; Abuku et al. 2009a; Briggen et al. 2009; van Hooff et al. 2011; Foroushani et al. 2014). Huang and Li (2010) used an Eulerian multiphase (EM) model with RANS and showed that it can give accurate results for WDR on the windward facade of an isolated low-rise building. Kubilay et al. (2013) validated the EM model by comparing the WDR results with existing measurement data on a historical building with a high-rise tower. The user time spent for the simulation of WDR on an isolated building decreases significantly with the EM model compared to the LPT model ( $\sim 10$ times). Further validation studies were performed by comparing numerical results with two high-resolution WDR measurement datasets involving generic and idealized multi-building configurations composed of an array of cubic buildings (Kubilay et al. 2014b) and two wide buildings of different heights (Kubilay et al. 2015b). The validation studies showed that the average discrepancies of the numerical results are between $2.5 \%$ and $12.0 \%$. In a further development, the turbulent dispersion of raindrops has been implemented into the EM model for time-averaged WDR calculations by Kubilay et al. (2015a). It was shown that taking turbulent dispersion into account reduces the deviation between CFD simulations and field measurements, especially by correctly capturing the behaviour of the smaller droplets.

WDR intensity is used as a boundary condition in studies of moisture transport, water film runoff and cooling effect due to evaporation in the built environment. In such studies, WDR intensity is often considered uniform across large parts of the facade. This may lead to discrepancies as, in reality, WDR intensity is far from uniform across building facades, even in the simplest cases of isolated buildings. WDR intensity on a building is governed by a wide range of parameters, such as building geometry, environment topography, position on the building facade, wind speed, wind direction, rainfall intensity and raindrop-size distribution (Blocken and Carmeliet 2002). A typical surface wetting pattern shows large gradients both vertically and horizontally on a single windward facade of a simplified rectangular building (Blocken and Carmeliet 2006a). In multi-building environments, the wind-flow pattern around one building is further influenced by other buildings and becomes more complex. In turn, the presence of neighboring buildings influence the WDR exposure on each other (Blocken et al. 2009; Kubilay et al. 2014b, 2015b). In addition to the large-scale influences of building size and shape and of surrounding environment, small-scale facade details have a considerable impact on WDR intensity. Facade details influence also the droplet impact speed and impact angle. These two parameters, together with surface properties of building facades, govern the fate of the droplets after impingement on the facade, especially for droplet spreading (Lee et al. 2015).

There are several studies that involve WDR analysis on buildings with facade details. Hangan (1999) investigates the effectiveness of cornices at sheltering rain on a mid-rise building using CFD simulations. Blocken and Carmeliet (2002, 2007) compare the sheltering provided on a low-rise building with different roof-overhang lengths using field experiments and CFD simulations. Similarly, the field measurements by Ge and Krpan (2007) on a low-rise building show that the presence of a roof overhang can significantly reduce the WDR intensity especially on the upper part of the facade. Briggen et al. (2009) performed field measurements and CFD simulations on a tower building with facade details, such as recessed facade parts and a loggia. These studies mostly focus on reporting the results on existing buildings, rather than performing detailed parametric analysis of the influence of facade details. Recently, Foroushani et al. (2014) performed a parametric WDR study on the influence of roof-overhang length on the windward facade of a cubic building.

The EM model results in less computational effort compared to LPT models which require very high number of raindrops to achieve accurate results (Blocken and Carmeliet 2006a, 2007), especially in the case of geometries with small details. Furthermore, the EM model allows the estimation of the WDR intensity on all surfaces in increasingly complex geometries, e.g. facade details, roofs, street level. The present study considers an average mid-rise residential building with various 
facade details. The geometry of the building includes balconies, roof overhang and window sills. WDR simulations with the wind direction perpendicular to the facade are conducted and the influence of facade details are presented. In section 2, the governing equations of WDR are presented. Section 3 presents the building geometry, the computational domain and grid, the boundary conditions, the solution strategy and the solver settings. Section 4 presents the simulation results and the main findings of the study. In section 5, a measured rain event is applied to compare the rain exposure of different cases. Finally, sections 6 and 7 provide a general discussion and conclusion, respectively.

\section{Numerical model for WDR simulation}

In the present study, 3D steady Reynolds-averaged Navier-Stokes (RANS) with the realizable $k-\varepsilon$ model (Shih et al. 1995) is used for the incompressible wind flow simulations. Realizable $k-\varepsilon$ model was previously used in various numerical WDR studies and found to be an accurate model (Blocken and Carmeliet 2004, 2007; Kubilay et al. 2014b, 2015b). In the Eulerian multiphase (EM) model, the rain phase is regarded a continuum, as is the wind phase. Each class of raindrop size is treated as a different phase, as each group of raindrops with similar size will interact with the wind-flow field in a similar way.

\subsection{Governing equations of WDR}

For each separate rain phase, the following continuity and momentum equations are solved:

$$
\begin{aligned}
& \frac{\partial \alpha_{d}}{\partial t}+\frac{\partial \alpha_{d} \overline{u_{d, j}}}{\partial x_{j}}=0 \\
& \frac{\partial \alpha_{d} \overline{u_{d, i}}}{\partial t}+\frac{\partial \alpha_{d} \overline{u_{d, i}} \overline{u_{d, j}}}{\partial x_{j}}+\frac{\partial \alpha_{d} \overline{u_{d, i}^{\prime} u_{d, j}^{\prime}}}{\partial x_{j}}=\alpha_{d} g_{i}+\alpha_{d} \frac{3 \mu_{a}}{\rho_{w} d^{2}} \frac{C_{d} \operatorname{Re}_{R}}{4}\left(\overline{u_{i}}-\overline{u_{d, i}}\right)
\end{aligned}
$$

where $d$ denotes the raindrop diameter, $\alpha_{d}$ the phase fraction of rain phase $d, u_{d, j}$ denotes the velocity component of rain phase $d, u_{i}$ the velocity component of wind in direction $i, \rho_{w}$ the density of water, $\mu_{a}$ is the dynamic viscosity of air, $g$ the gravitational acceleration, $C_{d}$ the drag coefficient. $\operatorname{Re}_{R}$ denotes the relative Reynolds number calculated using the relative velocity between the air and rain phases. The overbar denotes Reynolds averaging. In Eq. (2), the terms on the left-hand side are the transient term, the mean convective flux and the turbulent flux. The terms on the right-hand side represent the gravity and the drag forces. Turbulent dispersion of droplets is due to turbulent motions modeled by the third term on the left-hand side. Turbulent dispersion was neglected in many earlier WDR modeling efforts (Choi 1993, 1994; Blocken and Carmeliet 2002; Blocken et al. 2009; Abuku et al. 2009a; Briggen et al. 2009; Huang and Li 2010) and discrepancies of the numerical results at lower wind speed regions were mainly attributed to the neglect of turbulent dispersion. In the EM model, by defining a response coefficient, $C_{t}$, velocity fluctuations in rain phases can be related to the velocity fluctuations in the wind:

$$
C_{t}^{2}=\frac{\overline{u_{d, i}^{\prime} u_{d, j}^{\prime}}}{\overline{u_{i}^{\prime} u_{j}^{\prime}}}=\frac{1}{1+\frac{t_{p}}{t_{f l}}}
$$

where $t_{p}$ denotes the particle relaxation time which is the rate of response of particle acceleration to the relative velocity between the particle and the carrier fluid. $t_{f l}$ denotes the Lagrangian fluid time scale which is the characteristic large eddy 
lifetime. The relations for $t_{p}$ and $t_{f l}$ are given in Eq. (4) (Shirolkar et al. 1996), where $k$ and $\varepsilon$ denote the turbulence kinetic energy and dissipation rate in air phase. For a more detailed description and validation of the turbulent dispersion modeling of raindrops, the reader is referred to Kubilay et al. (2015a). When the particle relaxation time gets smaller compared to the Lagrangian fluid time scale, as is the case for smaller raindrops, $C_{t}$ approaches the value of 1 . In such cases, raindrops are more influenced by fluctuations in wind velocity.

$$
t_{p}=\frac{4 \rho_{w} d^{2}}{3 \mu_{a} C_{d} \operatorname{Re}_{R}}, \quad t_{f l} \cong 0.2 \frac{k}{\varepsilon}
$$

The governing equations of rain phases are implemented by the authors into OpenFOAM ${ }^{\circledR} 2.2$ CFD code (OpenFOAM Foundation, 2013). It is an open-source, implicit, segregated, and double precision solver. The wind-driven rain solver used in the present study can be accessed at the following website: http://www.carmeliet.arch.ethz.ch/ResearchDatabase/WindDrivenRainFoam

\subsection{WDR parameters}

The WDR intensity is related to the unobstructed horizontal rainfall intensity by the specific catch ratio, $\eta_{d}(d)$, and the catch ratio, $\eta$. The specific catch ratio, $\eta_{d}(d)$, is related to rain phase $d$, while the catch ratio is related to the entire spectrum of raindrop diameters. After solving the governing equations Eqs. (1-2), the values of the WDR parameters can be obtained by using the following relations:

$$
\begin{aligned}
& \eta_{d}(d)=\frac{R_{w d r}(d)}{R_{h}(d)}=\frac{\alpha_{d}\left|V_{n}(d)\right|}{R_{h} f_{h}\left(R_{h}, d\right)} \\
& \eta=\int_{d} f_{h}(d) \eta_{d}(d) \mathrm{d} d
\end{aligned}
$$

where $R_{w d r}$ denotes the WDR intensity, $R_{h}$ the horizontal rain intensity through the horizontal plane, $f_{h}\left(R_{h}, d\right)$ the raindropsize distribution through the horizontal plane and $\left|V_{n}(d)\right|$ the velocity magnitude of the rain phase in the direction normal to the building facade. In the present study, the raindrop-size distribution by Best (1950) and the terminal velocities by Gunn and Kinzer (1949) have been used.

\section{Simulation settings and parameters}

The present paper focuses on two different studies. The first one is a parametric study that compares the surface wetting on the windward facades of simplified residential buildings with different roof-overhang lengths. The second one studies the influence of balconies and smaller facade details such as window sills.

\subsection{Building geometries}

The stand-alone mid-rise building being studied in this paper has dimensions of height $\times$ length $\times$ width of $19.30 \times 8.00 \times$ $16.00 \mathrm{~m}^{3}$. The building geometry for the parametric study of the influence of different roof-overhang lengths on WDR intensity is shown in Fig. 1(a). The roof of the building is flat and is bordered with a 1m-high parapet, as normally found in 
buildings with accessible roofs for safety reasons. Case 1 is the reference case without roof overhang, whereas case 2 and case 3 have roof overhangs of $0.75 \mathrm{~m}$ and $1.50 \mathrm{~m}$ long, respectively, with a total height of roof slab plus parapet of $1.30 \mathrm{~m}$.

The building geometry that studies the influence of facade details, namely balconies and window sills, on WDR intensity is shown in Fig. 1(b). This geometry is named case 4 and its roof-overhang dimensions are the same as case 3 in Fig. 1(a). The floor-to-floor distance is $3 \mathrm{~m}$. The balconies are $1.3 \mathrm{~m}$ high, $1.5 \mathrm{~m}$ long in $\mathrm{x}$-direction and $3 \mathrm{~m}$ wide in $\mathrm{z}$-direction and located on both sides of the building. The window sills are located on only one side of the building in order to see their impact on WDR intensity more clearly and to decrease the total number of simulations. The window sills are only $0.1 \mathrm{~m}$ high projecting from the facade by $0.1 \mathrm{~m}$. Therefore, it is safe to assume that the influence of window sills on the wind flow is only local and they do not have an impact on the WDR intensity on the other side of the building.

\subsection{Computational domain and grids}

The computational domain and the boundary conditions for the wind flow are shown in Fig. 2. The distances of the boundaries from the buildings satisfy the guidelines stated in Tominaga et al. (2008) and Franke et al. (2011). The blockage ratio of the building is $1.5 \%$ for the wind direction perpendicular to the building, sufficiently smaller than the maximum blockage ratio of $3.0 \%$ suggested in the guidelines. For the grid sensitivity analysis, three grids composed of mainly hexahedral cells are created. The medium grid consists of 2331855 cells. The coarser grid has 993293 cells, whereas the finer grid counts 3934192 cells. The grid-sensitivity analysis is conducted by comparing the components of mean wind velocity along two vertical lines: line 1 is $0.250 \mathrm{~L}$ away from the facade and line 2 is $0.125 \mathrm{~L}$ away from the facade where $\mathrm{L}=1.5 \mathrm{~m}$ is the roof-overhang length. Both lines are located in the centerplane and range the full height of the building. The streamwise and vertical velocity profiles along the lines as well as the positions of the lines are shown in Fig. 3. The differences between grids along line 1 are generally smaller than the differences along line 2 . The largest differences are observed for the vertical velocity along line 2 . Along line 1 , the average difference in streamwise velocity is $8.7 \%$ between coarse and medium grids and $0.7 \%$ between medium and fine grids. The average difference in vertical velocity is $7.1 \%$ between coarse and medium grids and $4.1 \%$ between medium and fine grids. Along line 2, the average difference in streamwise velocity is $11.3 \%$ between coarse and medium grids and $6.4 \%$ between medium and fine grids. The average difference in vertical velocity is $24.6 \%$ between coarse and medium grids and $3.5 \%$ between medium and fine grids.

The base grid, shown in Fig. 4(a), is chosen for the rest of the study. The computational grid for the building in Fig. 1(b) is shown in Fig. 4(b) and is similar in terms of cell sizes with respect to distances from the building surfaces. Note that the number of cells is higher in this case (3 679975 cells) compared to the chosen grid for the parametric study (2 331855 cells) in order to capture the influence of the surface features. The smallest cell height is $0.031 \mathrm{~m}$ on the building surfaces and $0.063 \mathrm{~m}$ on the ground. The average $y^{+}$is found to be 1525.8 on the ground surface and 1679.2 on the building surface.

\subsection{Boundary conditions}

\subsubsection{Boundary conditions for wind phase}

The inlet profile of mean wind speed is given by the typical log-law expression as described in Eq. (7). The inlet profiles of the turbulence kinetic energy $k$ and turbulence dissipation rate $\varepsilon$ are defined by Eqs. (8) and (9) following the definitions by Richards and Hoxey (1993). In Eqs. (7-9), $U(y)$ denotes the mean streamwise wind speed at a height $y$ above the ground plane, $u^{*}{ }_{A B L}$ the atmospheric boundary layer (ABL) friction velocity, $\kappa$ the von Karman constant ( 0.42 in the present study), $y_{0}$ the aerodynamic roughness length and $C_{\mu}$ a model constant. The aerodynamic roughness length $y_{0}$ is taken as $0.03 \mathrm{~m}$, representing a levelled country with low vegetation, e.g. grass (Wieringa 1992). 


$$
\begin{aligned}
& U(y)=\frac{u_{A B L}^{*}}{\kappa} \ln \left(\frac{y+y_{0}}{y_{0}}\right) \\
& k(y)=\frac{u_{A B L}^{*}{ }^{2}}{C_{\mu}^{0.5}} \\
& \varepsilon(y)=\frac{u_{A B L}^{*}{ }^{3}}{\kappa\left(y+y_{0}\right)}
\end{aligned}
$$

For wall treatment, the standard wall functions by Launder and Spalding (1974) with sand-grain roughness modification (Cebeci and Bradshaw 1977) are used. The occurrence of unintended streamwise gradients was reported in the vertical flow profiles (or horizontal inhomogeneity) due to the inconsistencies between the wall boundary conditions, the inlet boundary conditions, the surface roughness modeling and the computational grid (Blocken et al. 2007; Hargreaves and Wright 2007; O'Sullivan et al. 2011). In order to limit the horizontal inhomogeneity, the equivalent sand-grain roughness height, $k_{s}$, and the roughness constant, $C_{s}$, are determined by the following relation by Blocken et al. (2007) which is also valid for the wall functions with roughness modification in OpenFOAM (OpenFOAM Foundation, 2013):

$k_{s}=\frac{E y_{0}}{C_{s}}$

where $E$ is an empirical constant with a value of 9.793. The relation shown in Eq. (10) matches the ABL mean velocity profile at the inlet to the parameters of the wall functions with roughness modification. For the ground surface of the computational domain, $k_{s}$ is taken to be $0.03 \mathrm{~m}$ and $C_{s}$ is set as 9.793 , leading to an aerodynamic roughness length $y_{0}=0.03 \mathrm{~m}$. The building surfaces are assumed to be smooth $\left(k_{s}=0\right)$. For the top boundary, constant values are set for $U, k$ and $\varepsilon$ by using fixed values from the inlet profiles at the same height as suggested by Blocken et al. (2007). This is done in order to further limit the horizontal inhomogeneity, as other top boundary conditions, such as symmetry condition, can cause streamwise gradients. Although imposing constant values does not allow fluid to enter or exit the domain, the top boundary is far enough from the buildings not to cause a problem.

At the outlet boundary, a constant static gauge pressure of $0 \mathrm{~Pa}$ is set. Note that this gauge pressure is relative to the reference atmospheric pressure. This boundary condition at the outlet implies a fully developed flow at the outlet and should not interfere with the results as long as the outlet boundary is placed sufficiently away from the buildings (15H distance (Franke et al. 2011), see Fig. 2(a)). Symmetry conditions are applied on both sides of the domain.

\subsubsection{Boundary conditions for rain phases}

The values of rain-phase fraction, $\alpha_{d}$, and the rain-phase velocity, $u_{d, j}$, are defined at the inlet and top boundaries for each rain phase $\mathrm{d}$. The phase fraction for rain phase $d$ can be calculated as in Eq. (11), where $V_{t}(d)$ represents the terminal velocity of a raindrop with diameter $d$ :

$\alpha_{d}=\frac{R_{h} f_{h}\left(R_{h}, d\right)}{V_{t}(d)}$ 
The vertical inlet rain phase velocity component is set equal to the terminal velocity for that phase. The horizontal component of rain-phase velocity is set such that there is a local force equilibrium between the rain and wind phases so that the droplets neither accelerate nor decelerate in an unobstructed computational domain.

The boundary conditions for the rain-phase fraction and the rain-phase velocity at the building walls, on the ground and at the outlet are set in such way that the normal gradient of the phase fraction, $\partial \alpha_{d} / \partial n$, equals zero when the normal wind velocity vector is pointing out of the domain, and the values of the phase fraction, $\alpha_{d}$, are equal to zero when the normal wind velocity vector is pointing into the domain. With these boundary conditions, the interaction between the raindrops and the walls are not modeled and the raindrops leave the domain as soon as they hit a wall boundary, avoiding any inflow of rain phase into the domain due to possible recirculation regions.

\subsection{Solution strategy}

The following steps have been followed to obtain the WDR solution:

a) The wind-flow field around the building is solved for a reference wind speed of $U_{10}=10 \mathrm{~m} / \mathrm{s}$ for a wind direction perpendicular to the building facade, where $U_{10}$ denotes the mean wind speed at $\mathrm{y}=10 \mathrm{~m}$ height from the ground. The wind-flow fields for other values of the reference wind speed ( $U_{10}=1,3$ and $\left.5 \mathrm{~m} / \mathrm{s}\right)$ are obtained by linear scaling.

b) The turbulent viscosity, $v_{t}$, is scaled linearly for the reference wind speed values, $U_{10}=1,3$ and $5 \mathrm{~m} / \mathrm{s}$. Similarly, the turbulence kinetic energy, $k$, is scaled quadratically and the turbulence dissipation rate, $\varepsilon$, is scaled cubically.

c) The governing equations for the rain phases are solved and specific catch ratio distributions are calculated for several raindrop diameters (17 diameters ranging from 0.3 to $1 \mathrm{~mm}$ in steps of $0.1 \mathrm{~mm}$, from 1 to $2 \mathrm{~mm}$ in steps of $0.2 \mathrm{~mm}$ and from 2 to $6 \mathrm{~mm}$ in steps of $1 \mathrm{~mm}$ ).

d) Catch ratio distributions are obtained for 16 reference horizontal rainfall intensities of $R_{h}=0,0.1,0.5,1,2,3,4,5$, $6,8,10,12,15,20,25$ and $30 \mathrm{~mm} / \mathrm{h}$ using the droplet-size distribution as input for each reference wind speed.

\subsection{Solver settings}

The pressure-velocity coupling for the wind-flow field solution is taken care of with the Semi-Implicit Method for Pressure Linked Equations (SIMPLE) algorithm. Rain phase calculations are one-way coupled with the air phase, with the effect of raindrops on the wind flow ignored. This is a valid assumption as the volumetric ratio of rain in air is below $1 \times 10^{-3}$ for rainfall intensities up to $20 \mathrm{~mm} / \mathrm{h}$ and below $1 \times 10^{-2}$ for even the most severe cases according to the study by de Wolf (2001).

Second-order discretization schemes are used for both the convection terms and the viscous terms of the governing equations. For both the air and rain phase calculations, the simulations are terminated when all the scaled residuals reach

$10^{-6}$. For each case, the calculation of wind-flow field took about 12 hours to converge on a parallel run with 16 processors. The calculation of rain phases, i.e. $d=0.3-6.0 \mathrm{~mm}$, took 6 to 10 hours to converge for each reference wind speed for each case.

\section{Results}




\subsection{Flow patterns of wind and rain}

The influence of the roof overhang on the flow field is presented in the vertical centerplane in Fig. 5 for cases 1, 2 and 3. Typical flow features such as standing vortex, recirculation region at the rooftop, downwards flow from the stagnation point and large vortex behind the building are visible. As the roof-overhang length increases, the stagnation point on the windward facade moves upwards. Such displacement will have an influence on the movement of raindrops near the windward facade. Furthermore, as the roof-overhang length increases, so does the length of the recirculation region at the rooftop. This causes the shear layer above the rooftop to shift, which pushes the center of the vortex downstream of the building slightly downwards. No significant difference is observed in terms of the standing vortex. Fig. 6 presents the influence of balconies on the wind-flow field by the comparing cases 3 and 4 around the top windward corner of the building. Velocity vectors and contours of mean wind speed are shown in the horizontal and vertical centerplanes of the balcony. The presence of balcony leads to two separation zones in the horizontal plane, i.e. one at the edge of the balcony and one at the edge of the building. This leads to lower wind velocity around the edge compared to case 3 . The flow fields in vertical planes in both cases show an out-of-plane movement towards the side of the building. A recirculation region within the balcony is visible both in vertical and horizontal planes.

Fig. 7(a) compares the trajectories for raindrop size $d=1.0 \mathrm{~mm}$ equidistantly injected away from the building along a line in the vertical center plane, i.e. $z=0$, for cases 1 and 3 for reference wind speed of $U_{10}=5 \mathrm{~m} / \mathrm{s}$. The influence of the roof overhang is clearly visible for the droplets impinging on the upper parts of the buildings. For case 1, the impact angle is larger at the top part, i.e. making larger angle with the surface or more perpendicular to the surface. On the other hand, for case 3 , the overhang is sheltering a considerable part of the upper facade and directing the droplets downwards. Also note that, for both cases, at the lower parts of the facade, the raindrops move almost parallel to the facade. This is due to the wind flow directed downwards at those regions (see Fig. 5). Fig. 7(b) presents the influence of balconies by comparing trajectories of raindrops around the top floor for cases 3 and 4 for reference wind speed of $U_{10}=5 \mathrm{~m} / \mathrm{s}$. Raindrops are of size $d=1.0 \mathrm{~mm}$ and are equidistantly injected along a line in the vertical plane $\mathrm{z}=3.5 \mathrm{~m}$. Balconies have an effect in a similar way to the roof overhang and further shelter the facade of the building. For case 4, the raindrops impinge on the outer surfaces or floors of balconies.

\subsection{Analysis of catch ratio}

Fig. 8 shows the distribution of catch ratio for a reference wind speed of $U_{10}=5 \mathrm{~m} / \mathrm{s}$ and a reference rainfall intensity of $R_{h}=1 \mathrm{~mm} / \mathrm{h}$ on all surfaces of the buildings and the ground for cases 3 and 4 . For case 3 , the catch ratio distribution on the ground shows a region of higher catch ratio $(\eta>1)$ with a horseshoe shape. This is due to the raindrops that are pushed downwards close to the windward facade and the raindrops that are accelerated around the side edges. For case 4 , some of the raindrops moving around the side edges of the building are blocked by the balconies. For both cases, there is also a gradient of catch ratio in the streamwise direction on the rooftop. This is due to the sheltering provided by the parapet and the acceleration of wind above the parapet.

\subsubsection{Influence of roof overhang}

Fig. 9(a) compares the distributions of catch ratio on the windward facades of cases 1,2 and 3 for wind speed of $U_{10}=5 \mathrm{~m} / \mathrm{s}$. The catch ratio distribution is calculated for a reference rainfall intensity of $R_{h}=1 \mathrm{~mm} / \mathrm{h}$. The catch ratio distribution on the windward facade of case 1 shows the common characteristics of WDR wetting, i.e. top and side edges have larger catch ratio values while the maximum catch ratio values are at the top corners. As the roof overhang length increases, the maximum catch ratio values slightly increase, i.e. the top corners of the roof overhang of case 3 have slightly 
higher catch ratio than the ones of case 2 , which also have slightly higher values than the ones of reference case 1 . On the other hand, the catch ratio values on the actual facade of the building decrease sharply at the upper part. Furthermore, the sheltered region grows towards the ground as the roof-overhang length increases. For case 2, the highest values are around 0.5 for a small area at the upper sides of the facade. For case 3, the highest values are below 0.4 and located at a lower position at the sides of the facade. Fig. 9(b-d) compare the specific catch ratio on the windward facades of cases 1, 2 and 3 for raindrop sizes of $0.5,1.0$ and $3.0 \mathrm{~mm}$ for the same reference wind speed. Similar trends are also visible as the roofoverhang length increases. For $0.5 \mathrm{~mm}$ droplets, the gradient on the facade is larger with higher values at the top and lower values at the bottom. For $3.0 \mathrm{~mm}$ droplets, the values are much more uniform. The sheltered region by roof overhang extends as the droplets get smaller. This is due to the fact that more of the smaller droplets are pushed downwards by the wind flow. The $3.0 \mathrm{~mm}$ droplets are less influenced by wind flow and, hence, larger specific catch ratios for $3.0 \mathrm{~mm}$ droplets are observed in the middle of the facade in cases 2 and 3. However, note that, the catch ratio values do not increase monotonically as droplet size increases, i.e. values for $0.5 \mathrm{~mm}$ droplets are also larger in the middle of the facade than the ones for $1.0 \mathrm{~mm}$ droplets. Catch ratio distributions are influenced by a combination of sheltering, flow field and turbulent dispersion (Kubilay et al. 2015b). For larger droplets, sheltering is more dominant, whereas smaller droplets are influenced more by flow field and turbulent dispersion.

Fig. 10 compares the catch ratio charts between cases 1, 2 and 3 at three rectangular areas. A catch ratio chart shows the catch ratio at a certain position as a function of reference rainfall intensity and reference wind speed. The catch ratio values are surface averaged over the rectangular areas, which represent the building facade on the first, third and fifth floors at the side of the building. Note that these areas correspond to the parts of the facade located behind the balconies in case 4 . The sheltering provided by different roof-overhang lengths are presented in Fig. 11. Sheltering ratio $\delta_{i-j}$ corresponds to the ratio between the decrease in catch ratio and the unsheltered catch ratio, which defined as:

$$
\delta_{i-j}=\frac{\eta_{i}-\eta_{j}}{\eta_{i}}
$$

where $\eta_{i}$ and $\eta_{j}$ correspond to the catch ratio values obtained in cases $i$ and $j$, respectively. Similar methods to quantify sheltering are also proposed by Hangan (1999) and Foroushani et al. (2014).

The following main outcomes can be deduced from Fig. 10 and Fig. 11. Firstly, the maximum sheltering due the presence of roof overhangs is observed at the lowest reference wind speed at all floors. This is due to the fact that, as wind speed increases, the raindrops gain a larger horizontal velocity and become more parallel to the ground, which decreases the sheltering. Secondly, sheltering provided by case 3 is higher than the one provided by case 2 due to larger roof-overhang length. For example, sheltering provided by case 2 decreases to very small values for wind speeds higher than $3 \mathrm{~m} / \mathrm{s}$ at floors 1 and 3 . On the other hand, for $U_{10}=3 \mathrm{~m} / \mathrm{s}$, case 3 still provides a sheltering between $35 \%-51 \%$ at floor 3 and a sheltering between $8 \%-12 \%$ at floor 1 . The decrease in sheltering for case 3 happens at wind speeds higher than $5 \mathrm{~m} / \mathrm{s}$. At the fifth floor, there is a large difference between all cases at all reference wind speeds and rainfall intensities. Even for the highest reference wind speed of $10 \mathrm{~m} / \mathrm{s}$, where raindrops move more horizontal compared to lower wind speeds, Fig. 10(a) and Fig. 11(a) show, for $R_{h}=10 \mathrm{~mm} / \mathrm{h}$, a difference of about $20 \%$ between cases 1 and 2 and of about $40 \%$ between cases 1 and 3. Thirdly, the maximum sheltering tends to decrease as rainfall intensity increases. This is due to the fact that, at higher rainfall intensities, larger droplets, present in a proportionally larger fraction, are less shielded by the presence of the roof overhang compared to what smaller droplets would undergo (see Fig. 9). For example, at the first floor, for reference wind speed of $1 \mathrm{~m} / \mathrm{s}$, case 2 provides about $74 \%$ sheltering for $R_{h}=1 \mathrm{~mm} / \mathrm{h}$ and about $60 \%$ sheltering for $R_{h}=10 \mathrm{~mm} / \mathrm{h}$. A similar decrease in sheltering is also visible at the third and fifth floors at low wind speeds for case 2 as rainfall intensity 
increases. Case 3 provides full sheltering for all floors at all rainfall intensities at $U_{10}=1 \mathrm{~m} / \mathrm{s}$. However, at $U_{10}=3 \mathrm{~m} / \mathrm{s}$, a decrease in sheltering is also visible for case 3 with increasing rainfall intensity. At the third floor, for a reference wind speed of $3 \mathrm{~m} / \mathrm{s}$, case 3 provides about $48 \%$ sheltering for $R_{h}=1 \mathrm{~mm} / \mathrm{h}$ and about $38 \%$ sheltering for $R_{h}=10 \mathrm{~mm} / \mathrm{h}$.

\subsubsection{Influence of balconies and window sills}

Fig. 12 shows the distributions of catch ratio and specific catch ratio on the windward facade of case 4 for a wind speed of $U_{10}=5 \mathrm{~m} / \mathrm{s}$. The catch ratio distribution is calculated for a reference rainfall intensity of $R_{h}=1 \mathrm{~mm} / \mathrm{h}$. Specific catch ratio distributions are for raindrop sizes of $0.5,1.0$ and $3.0 \mathrm{~mm}$. The catch ratio values on the facade of case 4 are much lower than the ones on the facade of case 3. However, this time, the front walls of the balconies receive a higher amount of WDR compared to what the facade would receive, especially the balconies at the top floor. Similar to Fig. 9, specific catch ratios for $3.0 \mathrm{~mm}$ droplets are larger in the middle of the facade. On the right side of the facade, the window sills decrease the catch ratio values even more by providing additional sheltering, especially at the lower floors, where the droplets move more parallel to the facade. The window sills decrease the average catch ratio by $19.0 \%$ (from 0.21 to 0.17 ) at the third floor and by $37.5 \%$ (from 0.16 to 0.10 ) at the first floor.

Fig. 13 compares the catch ratio charts for cases 3 and 4 using surface-averaged catch ratio values over different areas situated at the first, third and fifth floors of the building in two planes. The areas are in the plane of the facades of the building for cases 3 and 4 and in the plane of the front walls of the balconies for case 4 as indicated in the figure. At all floors, the outer walls of balconies are exposed to more WDR, even more so than case 1, which has no roof overhang. The reasons for this are that, first, the balconies extend out of the building facade where the roof overhang has no influence and, second, the acceleration of wind flow around the edges of the balconies increases the WDR intensity. On the other hand, the presence of the balconies results in a major decrease of the average catch ratio on the building facade compared to case 3 . This is the case even at the fifth floor, which is already sheltered by the presence of the longer roof overhang.

The sheltering ratio between the facades of the building for cases 3 and 4 are given in Fig. 14 with respect to reference rainfall intensity and reference wind speed values. The following main outcomes can be deduced from Fig. 14. First, the largest sheltering effect of the balconies on the facade is observed at the first and third floors. At these floors, the building facade behind the balconies is largely sheltered by the balcony of the upper floor which acts as a local roof overhang, whereas, in case 3, there is no such sheltering for these floors. The sheltering is over $90 \%$ up to wind speed of $3 \mathrm{~m} / \mathrm{s}$, over which it decreases slightly, but still remains over $60 \%$ at $U_{10}=10 \mathrm{~m} / \mathrm{s}$. Second, at the lower floors, the sheltering is almost independent of the $U_{10}$ and $R_{h}$ couples, being generally over $85 \%$. Third, at the fifth floor, the balconies shelter the building facade further compared to case 3 where there is only roof overhang. The sheltering is over $85 \%$ at wind speed of $3 \mathrm{~m} / \mathrm{s}$ for all rainfall intensities. The sheltering amount decreases to about between $30-40 \%$ at $U_{10}=5 \mathrm{~m} / \mathrm{s}$ and is about $20 \%$ for $U_{10}=$ $10 \mathrm{~m} / \mathrm{s}$.

\subsection{Analyses of droplet impact speed and impact angle}

For a complete analysis of WDR in the built environment, the phenomena after the droplet impact, such as droplet spreading, splashing, bouncing, absorption, evaporation, film forming and run-off on building facades, should be taken into account. The fate of the rain droplets after impact can be modeled using impact velocity, impact angle and the surface properties (Abuku et al. 2009b; Lee et al. 2015). The CFD simulations of WDR give detailed information on the distribution of these two critical parameters, i.e. droplet impact speed and impact angle. Fig. 15(a) compares the distribution of droplet impact speed for raindrop size of $d=1.0 \mathrm{~mm}$ on the windward facades for wind speed of $U_{10}=5 \mathrm{~m} / \mathrm{s}$. The impact speed shows different characteristics compared to the catch ratio distribution shown in Fig. 9. For the reference case 1, the lowest 
impact speed is observed at the upper parts where the wind flows upwards above the stagnation point on the windward facade. Impact speed is about two times higher at the lower parts of the building due to the fact that droplets are accelerated downwards by the downward wind flow near the lower parts of the facade. At the lower parts, near the side edges, the values are even higher due to further acceleration of wind flow around the side edges of the building. As the roof-overhang length increases, in cases 2 and 3, the sheltered regions below the roof overhangs are visible, as also shown in Fig. 9. Similarly, in case 4, due to the presence of balconies and window sills, the highest impact speed is lower. Window sills help to decrease the raindrop impact speed considerably at the lower parts of the building as they perturb the downward wind flow. Window sills decrease the average droplet impact speed for $1.0 \mathrm{~mm}$ droplets by $22.4 \%$ (from $4.59 \mathrm{~m} / \mathrm{s}$ to $3.56 \mathrm{~m} / \mathrm{s}$ ) at the third floor and by $39.8 \%$ (from $5.85 \mathrm{~m} / \mathrm{s}$ to $3.52 \mathrm{~m} / \mathrm{s}$ ) at the first floor.

Fig. 15(b) compares the distribution of droplet impact angle for raindrop size of $d=1.0 \mathrm{~mm}$ on the windward facades for wind speed of $U_{10}=5 \mathrm{~m} / \mathrm{s}$. Impact angle values are given with respect to the surface, i.e. impact angle of $90^{\circ}$ corresponds to droplets impinging perpendicularly to the surface. For all cases, the highest values are observed at the top of the building where the flow is accelerated around the windward edge, which pushes the droplets upwards (see Fig. 7). Similar effect is also present at the outer surfaces of balconies for case 4, where larger impact angles are observed.

\section{Application based on a measured rain event}

Kubilay et al. (2014a) and Kubilay et al. (2015b) reported field measurements of WDR in Dübendorf in a suburban area located east of the city of Zurich, Switzerland, latitude $47^{\circ} 24^{\prime} 9^{\prime \prime}$ and longitude $8^{\circ} 36^{\prime} 50^{\prime \prime}$. The measurement location was on the campus of the Swiss Federal Laboratories for Materials Science and Technology (Empa). In this section, a measured rain event from these WDR campaigns is used to compare the WDR intensities for different cases. Since the analysis of WDR is performed for a single wind direction in the present study, i.e. wind direction perpendicular to the main facade of the building, a rain event is chosen such that the wind direction can be assumed constant. Fig. 16(a) shows the meteorological data over time measured during the rain event on September 12, 2013 using 10-min experimental time steps. The rain event takes place within a time frame of about 9 hours. For the sake of this analysis, the main facade of the building is assumed to face towards west. The field measurements involved wind speed measurements at three different heights in order to obtain the approach-flow wind profile. Assuming a neutrally stratified atmospheric boundary layer profile, the wind speed at $10 \mathrm{~m}$ height, $U_{10}$, during the rain event is obtained as shown in Fig. 16(a).

Following the steps explained in section 3.4, the calculated catch ratio values for different wind speeds and rainfall intensities are interpolated based on the experimental data records at each 10-min experimental time step. This gives the spatial distributions of catch ratio at the end of the rain event, $\eta_{r e}$, defined as:

$\eta_{r e}=\frac{S_{w d r}}{S_{h}}$

where $S_{w d r}$ denotes the total WDR amount at the end of the rain event and $S_{h}$ the total rainfall amount. Fig. 16(b-e) show the distributions on the windward facades of cases 1-4. The highest values are observed at the top edges for all cases, $\eta_{r e}$ being about 0.5 , which means the building is exposed to half the total rainfall at these positions. The differences of rain deposition between the four cases follow the trends observed in section 4. For case 1, a large part of the upper facade and side edges have a catch ratio above 0.2. As the roof-overhang length increases, for cases 2 and 3 , the sheltered region on the facade gets larger. In these cases, the highest values, excluding the roof overhang itself, are observed at the edges of the facade and the values decrease as the roof-overhang length increases. For case 4, the catch ratio on the building facade further 
decreases and noteworthy catch ratios, between $0.1-0.3$, are observed on the balcony front walls. Note also that the small ridge detail at the top of the roof overhang is effective at decreasing the catch ratio on the roof overhang.

\section{Discussion}

The comparison of surface wetting in the present study shows that the sheltering due to overhang is highly significant and depends also on wind speed, rainfall intensity and position on the facade. As the roof overhang length increases, the sheltering is increased at higher wind speed values. Based on the large difference between the catch ratio values in Fig. 10(a), even very short roof overhangs decrease very high catch ratio values to more moderate values at the higher parts of the buildings. This is further illustrated in Fig. 12, where the additional overhang of a sill with a size of $0.10 \mathrm{~m}$ decreases the catch ratio values along the top edge to more moderate values. The balconies further decrease the average catch ratio on the windward facade, in addition to the influence of the roof overhang, especially at the lower floors. Here the balconies act themselves as local overhangs protecting the balconies below from WDR. Close to the roof overhang, the additional sheltering effect provided by the balcony reduces, although the average catch ratio is still lower compared to the case without balcony.

For all cases, the lower parts of the building are exposed to higher raindrop impact speed due to downward acceleration by wind flow. Even though the WDR intensity is lower at lower parts of the building, the higher impact speed might be interesting in terms of comfort-related design studies, surface-erosion studies or moisture-related studies as the impact speed influences the fate of the droplets after impingement, e.g. splashing, absorption. Relatively small facade modulations, such as the window sills of a size of $0.10 \mathrm{~m}$, are found to decrease the impact speed as well as the catch ratio, by influencing the wind-flow field around the windward facade. Note that, in the present study, the numerical simulations considered only the wind direction perpendicular to a single facade of the building, as the main focus of this paper was not the influence of wind direction.

The EM model has been validated using data obtained from WDR field experiments in various geometries. Kubilay et al. (2015a) performed a validation study on a building with tower of a similar size to the building in the present study.

Kubilay et al. (2014b, 2015b) performed validation studies using field data of WDR on building models with sizes of 2 to $6 \mathrm{~m}$. Based on these validation studies and given that the flow structures due to balconies are of similar size to the ones experienced around the $2 \mathrm{~m}$ buildings, the model is assessed to perform accurately for WDR on balconies. However, the buildings in the present study are more detailed and complicated than the validation geometries. It is likely that the WDR intensity in the present study have discrepancies around the smaller features, i.e. window sills. Furthermore, apart from the discrepancies in the WDR model, the accuracy is also influenced by the deficiencies of steady RANS models related to separation regions (Murakami 1993; Tominaga et al. 2008), e.g. around balconies and window sills. It is assumed that the sensitivity of raindrops to these deficiencies is limited. This assumption is valid as rainfall intensity increases, in which case there will be more large droplets with higher inertia. On the other hand, validating the numerical model for the influence of small details can be difficult using field measurements, as wind-driven rain gauges tend to have collecting areas larger than window sills or others (Blocken and Carmeliet 2006b).

In terms of computational complexity and post-processing, the present study is performed without any additional requirements or adjustments even though the building geometries are complicated. WDR calculations with the EM model proved to have a higher practicality compared to the LPT modeling in terms of faster calculation time and ease of use. Furthermore, the catch ratio and the raindrop impact parameters, such as impact speed and impact angle are calculated on all

surfaces of a complex domain. The turbulent dispersion of raindrops is easily implemented in the EM model in steady WDR 
simulations increasing the accuracy of the simulation. These advantages allow to use the EM model as a design tool in WDR studies that involve complex buildings.

\section{Conclusion}

Numerical simulations of WDR are performed on a stand-alone mid-rise building. The catch ratio and raindrop impact speed are quantitatively compared on the windward facades with architectural detailing. Three of the four cases have geometries with identical straight facades but different roof overhang lengths. The fourth geometry has balconies at each floor on either side of the building, as well as window sills on one side. The results demonstrate the following outcomes:

- At high rainfall intensities, the regions sheltered by the roof overhang becomes smaller at the upper part of the building. Also, at high rainfall intensities, higher catch ratio values are observed in the middle and lower parts of the facade.

- As the wind speed increases, sheltering provided by roof overhang and balconies decreases as the raindrops move more horizontally.

- Parts of buildings that extend out, such as roof overhang and balconies, are effective at sheltering the facade from WDR, but are themselves exposed to a higher amount of WDR compared to a flat facade due to acceleration of wind flow around their edges.

- Windows sills are very effective at decreasing catch ratio and droplet impact speed to more moderate values, especially at low rainfall intensities and at lower parts of the building. It is found that window sills decrease the average catch ratio by $19 \%$ at the third floor and by $38 \%$ at the first floor for $U_{10}=5 \mathrm{~m} / \mathrm{s}$ and $R_{h}=1 \mathrm{~mm} / \mathrm{h}$. They decrease the average droplet impact speed for $1.0 \mathrm{~mm}$ droplets by $22 \%$ at the third floor and by $40 \%$ at the first floor for $U_{10}=5 \mathrm{~m} / \mathrm{s}$.

- Contours of catch ratio on the ground show a high WDR intensity region around the building resembling a horseshoe shape for wind direction perpendicular to the main facade.

Furthermore, a measured rain event is applied to compare the catch ratio distributions between different cases. The difference in distributions at the end of the rain event are similar to the ones observed in the specific analyses. The resulting distributions are due to different combinations of wind speed and rainfall intensity values during the rain event. Based on its ease of use in terms of setting the boundary conditions for WDR calculations, as well as the calculation procedure which uses the same computational grid as wind-flow calculations, the EM model proves to be a practical solution for parametric WDR studies, as well as design-related WDR studies.

\section{Acknowledgments}

The research was supported through the Swiss National Science Foundation (SNF) - Project no. 135510. 


\section{References}

Abuku, M., Blocken, B., Nore, K., Thue, J.V., Carmeliet, J., and Roels, S. 2009a. On the validity of numerical wind-driven rain simulation on a rectangular low-rise building under various oblique winds. Build Environ 44 (3):621-632.

Abuku, M., Janssen, H., Poesen, J., and Roels, S. 2009b. Impact, absorption and evaporation of raindrops at building facades. Build Environ 44 (1):113-124.

Abuku, M., Janssen, H., and Roels, S. 2009c. Impact of wind-driven rain on historic brick wall buildings in a moderately cold and humid climate: Numerical analyses of mould growth risk, indoor climate and energy consumption. Energ Buildings 41 (1):101-110.

Barberousse, H., Ruot, B., Yéprémian, C., and Boulon, G. 2007. An assessment of façade coatings against colonisation by aerial algae and cyanobacteria. Build. Environ. 42 (7):2555-2561.

Best, A.C. 1950. The size distribution of raindrops. Q J Roy Meteor Soc 76 (327):16-36.

Blocken, B. 2014. 50 years of Computational Wind Engineering: Past, present and future. J Wind Eng Ind Aerod 129 (0):69-102.

Blocken, B., and Carmeliet, J. 2002. Spatial and temporal distribution of driving rain on a low-rise building. Wind Struct 5 (5):441-462.

Blocken, B., and Carmeliet, J. 2004. A review of wind-driven rain research in building science. J Wind Eng Ind Aerod 92 (13):1079-1130.

Blocken, B., and Carmeliet, J. 2006a. The influence of the wind-blocking effect by a building on its wind-driven rain exposure. $J$ Wind Eng Ind Aerod 94 (2):101-127.

Blocken, B., and Carmeliet, J. 2006b. On the accuracy of wind-driven rain measurements on buildings. Build Environ 41(12):1798-1810.

Blocken, B., and Carmeliet, J. 2007. Validation of CFD simulations of'wind-driven rain on a low-rise building facade. Build Environ 42 (7):2530-2548.

Blocken, B., and Carmeliet, J. 2010. Overview of three state-of-the-art wind-driven rain assessment models and comparison based on model theory. Build Environ 45 (3):691-703.

Blocken, B., Dezso, G., van Beeck, J., and Carmeliet, J. 2009. The mutual influence of two buildings on their wind-driven rain exposure and comments on the obstruction factor. J Wind Eng Ind Aerod 97 (5-6):180-196.

Blocken, B., Stathopoulos, T., and Carmeliet, J. 2007. CFD simulation of the atmospheric boundary layer: wall function problems. Atmos Environ 41 (2):238-252.

Briggen, P.M., Blocken, B., and Schellen, H.L. 2009. Wind-driven rain on the facade of a monumental tower: numerical simulation, fullscale validation and sensitivity analysis. Build Environ 44 (8):1675-1690.

Cebeci, T., and Bradshaw, P. 1977. Momentum transfer in boundary layers. New York: Hemisphere Publishing Corporation.

Charola, A.E., and Lazzarini, L. 1986. Deterioration of brick masonry caused by acid rain. ACS Symp. Series 318:250-258.

Choi, E.C.C. 1991. Numerical simulation of wind-driven rain falling onto a 2-D building. Asia Pacific Conf. on Computational Mechanics, Hong Kong.

Choi, E.C.C. 1993. Simulation of wind-driven-rain around a building. J Wind Eng Ind Aerod 46-47:721-729.

Choi, E.C.C. 1994. Determination of wind-driven-rain intensity on building faces. J Wind Eng Ind Aerod 51 (1):55-69.

Choi, E.C.C. 2002. Modelling of wind-driven rain and its soil detachment effect on hill slopes. J Wind Eng Ind Aerod 90 (9):1081-1097.

Davidson, C.I., Tang, W., Finger, S., Etyemezian, V., Striegel, M., and Sherwood, S.I. 2000. Soiling patterns on a tall limestone building: changes over 60 years. Environ Sci Technol 34 (4):560-565.

de Wolf, D.A. 2001. On the Laws-Parsons distribution of raindrop sizes. Radio Sci 36 (4):639-642.

Erkal, A., D'Ayala, D., and Sequeira, L. 2012. Assessment of wind-driven rain impact, related surface erosion and surface strength reduction of historic building materials. Build Environ 57:336-348.

Etyemezian, V., Davidson, C.I., Zufall, M., Dai, W., Finger, S., and Striegel, M. 2000. Impingement of rain drops on a tall building. Atmos Environ 34:2399-2412.

Foroushani, M.S.S., Ge, H., and Naylor, D. 2014. Effects of roof overhangs on wind-driven rain wetting of a low-rise cubic building: A numerical study. J Wind Eng Ind Aerod 125 (0):38-51.

Franke, J., Hellsten, A., Schlunzen, K.H., and Carissimo, B. 2011. The COST 732 Best practice guideline for CFD simulation of flows in the urban environment: a summary. Int J Environ Pollut 44 (1-4):419-427.

Franke, L., Schumann, I., van Hees, R., van der Klugt, L., Naldini, S., Binda, L., Baronio, G., van Balen, K., and Mateus, J. 1998. Damage atlas: classification and analyses of damage patterns found in brick masonry. European Commision Research report No 8, vol. 2, Fraunhofer IRB Verlag.

Ge, H., and Krpan, R. 2007. Field measurement of wind-driven rain on a low-rise building in the coastal climate of British Columbia. Proceedings of the 11th Canadian Conference on Building Science and Technology, March, Banff, Alberta.

Gunn, R., and Kinzer, G.D. 1949. The terminal velocity of fall for water droplets in stagnant air. J Meteorol 6 (4):243-248.

Hangan, H. 1999. Wind-driven rain studies. A C-FD-E approach. J Wind Eng Ind Aerod 81:323-331.

Hargreaves, D.M., and Wright, N.G. 2007. On the use of the k-epsilon model in commercial CFD software to model the neutral atmospheric boundary layer. J Wind Eng Ind Aerod 95 (5):355-369.

Huang, S.H., and Li, Q.S. 2010. Numerical simulations of wind-driven rain on building envelopes based on Eulerian multiphase model. $J$ Wind Eng Ind Aerod 98 (12):843-857.

Kubilay, A., Derome, D., Blocken, B., and Carmeliet, J. 2013. CFD simulation and validation of wind-driven rain on a building facade with an Eulerian multiphase model. Build Environ 61:69-81.

Kubilay, A., Derome, D., Blocken, B., and Carmeliet, J. 2014a. High-resolution field measurements of wind-driven rain on an array of low-rise cubic buildings. Build Environ 78:1-13.

Kubilay, A., Derome, D., Blocken, B., and Carmeliet, J. 2014b. Numerical simulations of wind-driven rain on an array of low-rise cubic buildings and validation by field measurements. Build Environ 81 (0):283-295. 
Kubilay, A., Derome, D., Blocken, B., and Carmeliet, J. 2015a. Numerical modeling of turbulent dispersion for wind-driven rain on building facades. Environ Fluid Mech 15 (1):109-133.

Kubilay, A., Derome, D., Blocken, B., and Carmeliet, J. 2015b. Wind-driven rain on two parallel wide buildings: field measurements and CFD simulations. $J$ Wind Eng Ind Aerod 146:11-28.

Launder, B.E., and Spalding, D.B. 1974. The numerical computation of turbulent flows. Comput. Methods Appl. Mech. Eng. 3:269-289.

Lee, J.B., Laan, N., de Bruin, K.G., Skantzaris, G., Shahidzadeh, N., Derome, D., Carmeliet, J., and Bonn, D. 2015. Universal rescaling of drop impact on smooth and rough surfaces. J Fluid Mech 786:R4.

Murakami, S. 1993. Comparison of various turbulence models applied to a bluff body. J Wind Eng Ind Aerodyn 46-47:21-36.

OpenFOAM Foundation. 2013. OpenFOAM v2.2.2 User guide. Retrieved from http://www.openfoam.org.

O'Sullivan, J.P., Archer, R.A., and Flay, R.G.J. 2011. Consistent boundary conditions for flows within the atmospheric boundary layer. $J$

Wind Eng Ind Aerod 99 (1):65-77.

Richards, P.J., and Hoxey, R.P. 1993. Appropriate boundary conditions for computational wind engineering models using the k- $\epsilon$ turbulence model. J Wind Eng Ind Aerod 46-47 (0):145-153.

Shih, T.-H., Liou, W.W., Shabbir, A., Yang, Z., and Zhu, J. 1995. A new k- $€$ eddy viscosity model for high reynolds number turbulent flows. Comput Fluids 24 (3):227-238.

Shirolkar, J.S., Coimbra, C.F.M., and McQuay, M.Q. 1996. Fundamental aspects of modeling turbulent particle dispersion in dilute flows. Prog Energy Combust Sci 22:363-399.

Tang, W., and Davidson, C.I. 2004. Erosion of limestone building surfaces caused by wind-driven rain: 2. numerical modeling. Atmos Environ 38 (33):5601-5609.

Tang, W., Davidson, C.I., Finger, S., and Vance, K. 2004. Erosion of limestone building surfaces caused by wind-driven rain: 1. Field measurements. Atmos Environ 38 (33):5589-5599.

Tominaga, Y., Mochida, A., Yoshie, R., Kataoka, H., Nozu, T., Yoshikawa, M., and Shirasawa, T. 2008. AIJ guidelines for practical applications of CFD to pedestrian wind environment around buildings. J. Wind Eng. Ind. Aerodyn. 96 (10-11):1749-1761.

Van Balen, K. 1996. Expert system for evaluation of deterioration of ancient brick masonry structures. Sci Total Environ 189:247-254.

van Hooff, T., Blocken, B., and van Harten, M. 2011. 3D CFD simulations of wind flow and wind-driven rain shelter in sports stadia: Influence of stadium geometry. Build Environ 46 (1):22-37.

van Mook, F.J.R. 2002. Driving rain on building envelopes. In.: Ph.D. thesis, Eindhoven University of Technology, Eindhoven, The Netherlands.

Wieringa, J. 1992. Updating the Davenport roughness classification. J Wind Eng Ind Aerod 41 (1-3):357-368. 
Figures

a)
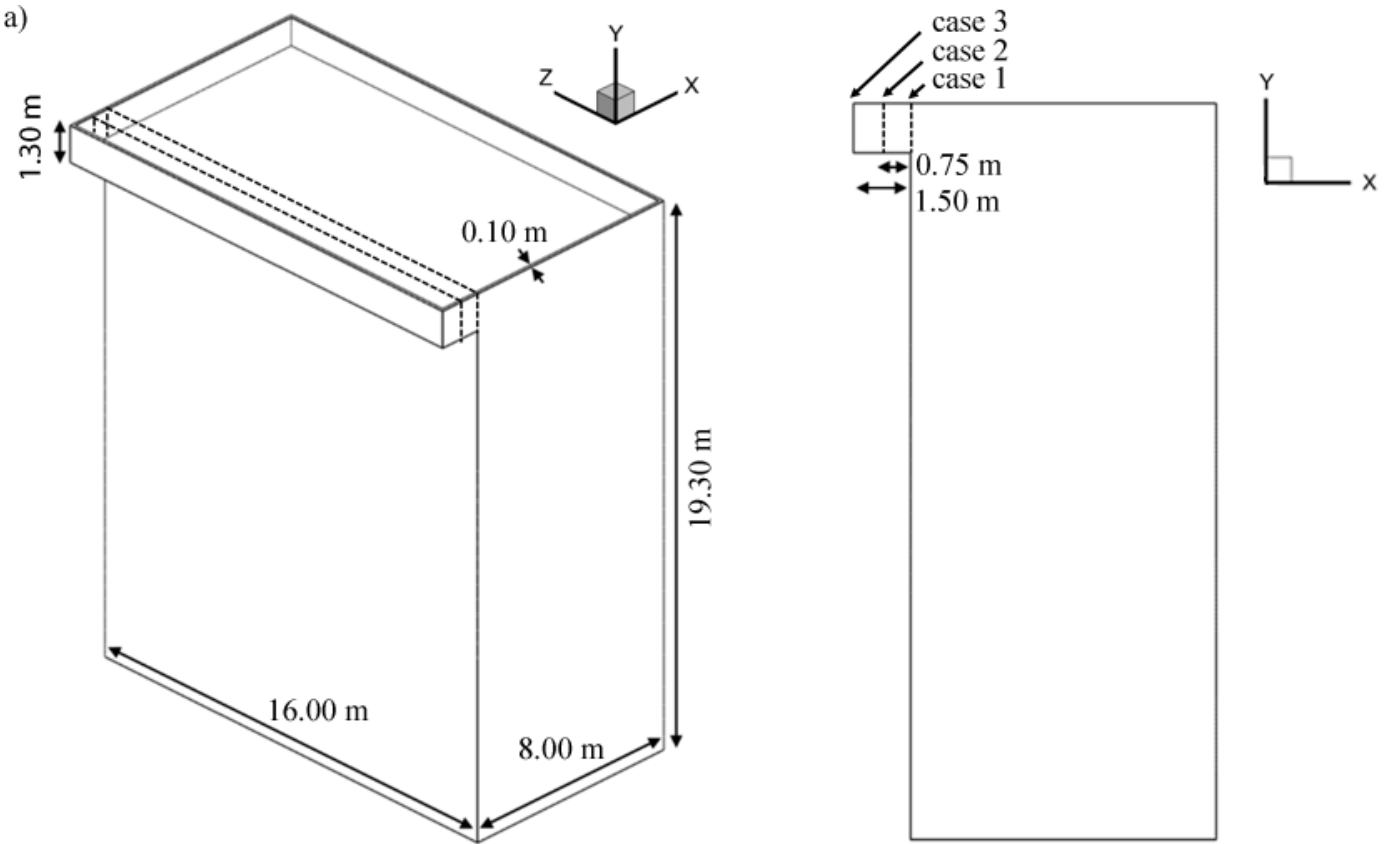

b)

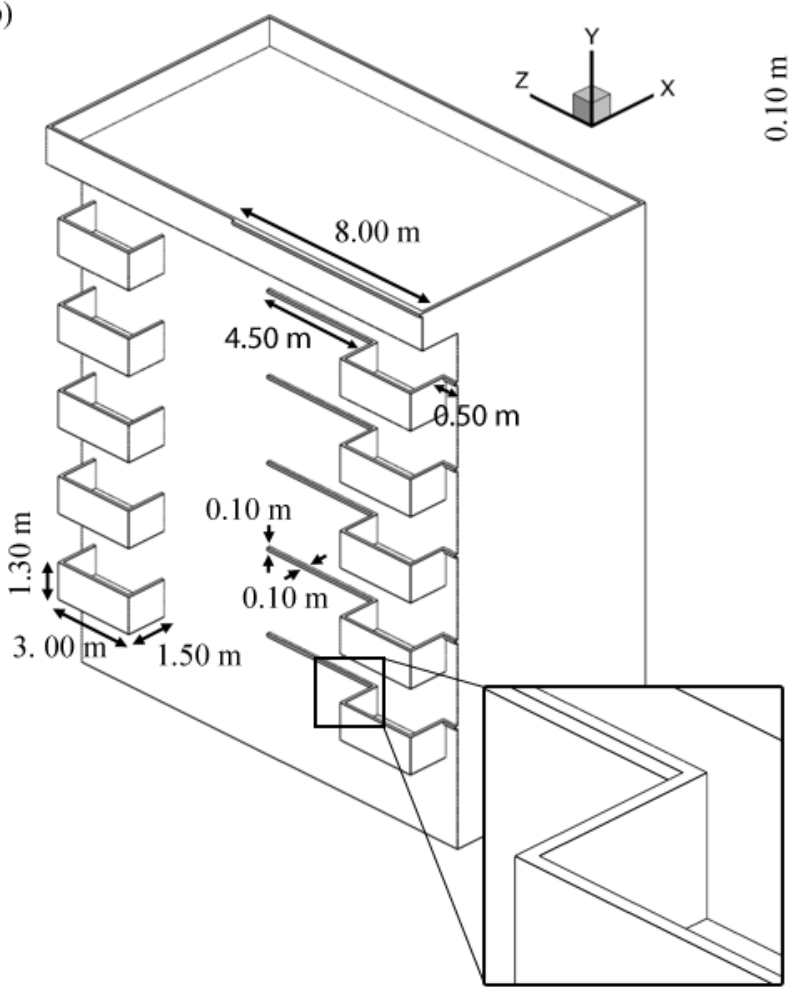

$0.10 \mathrm{~m}$

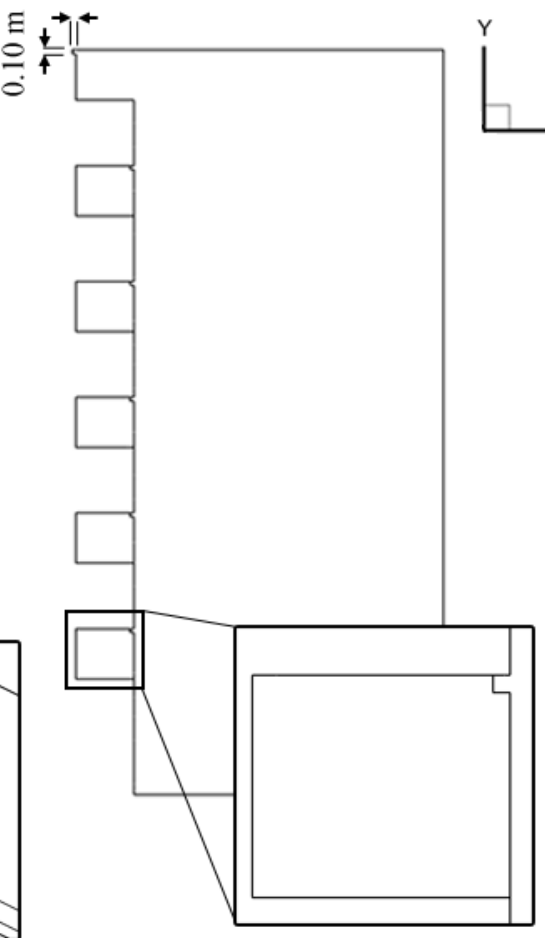

Fig. 1. Corner and side views of the building geometry a) cases 1, 2 and 3 for the parametric study of different roof overhang lengths and b) case 4 for facade details study with balconies and window sills. 
a)

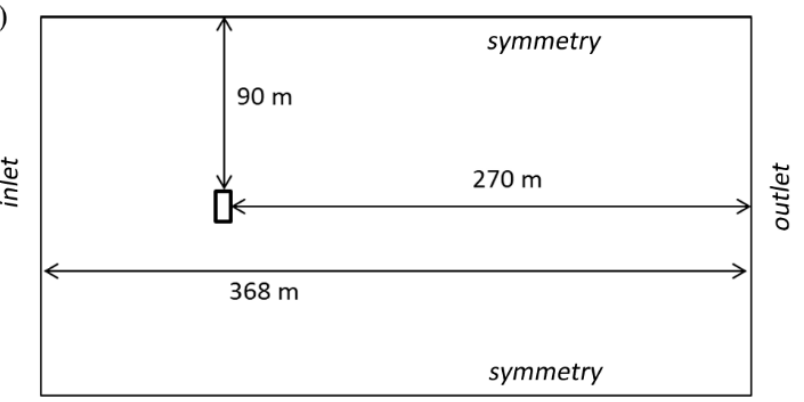

b)

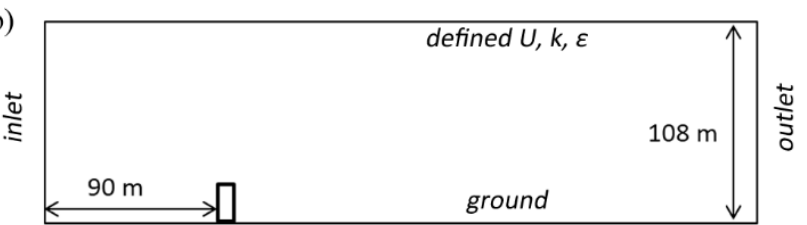

Fig. 2. Computational domain a) from top and b) from side.
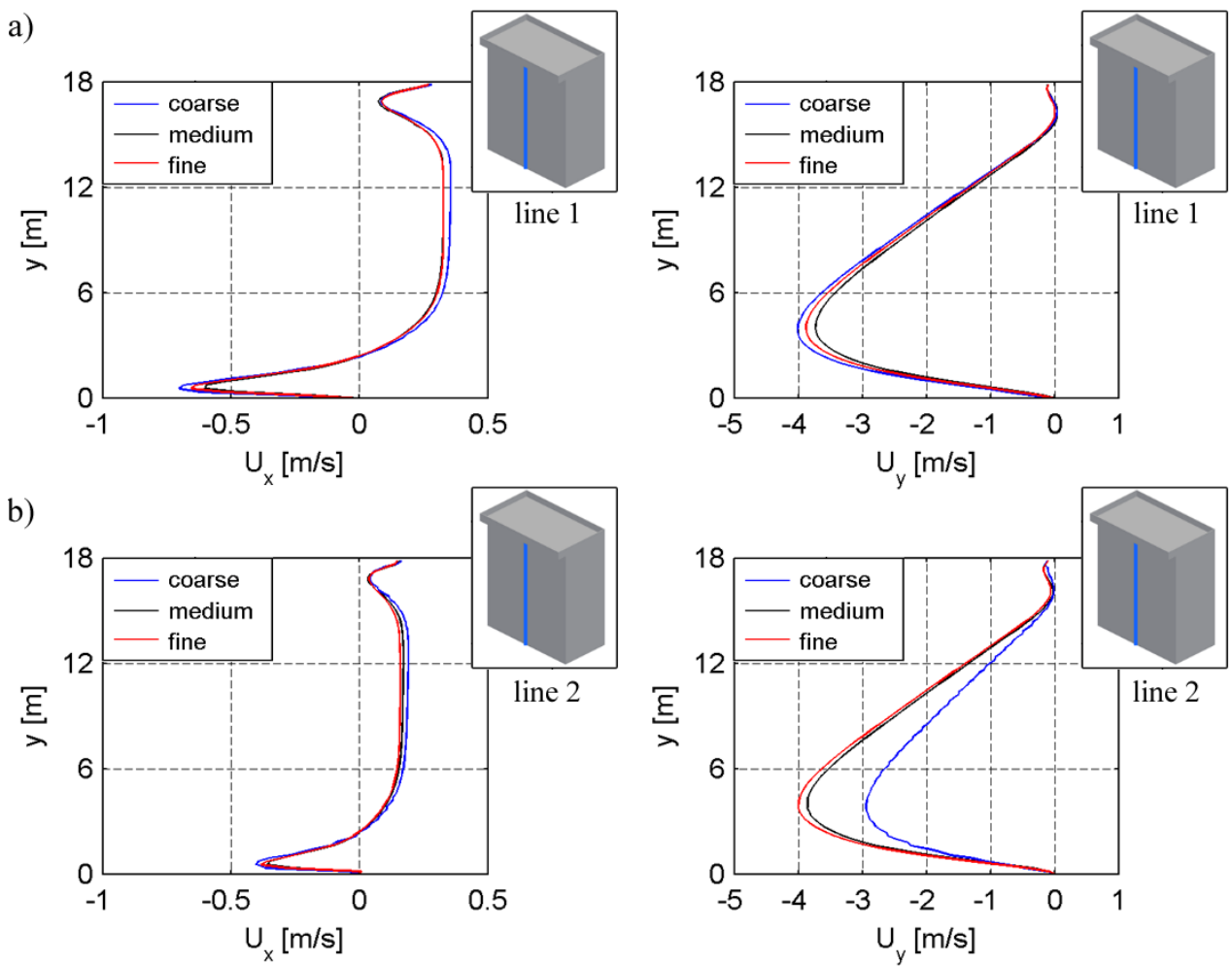

Fig. 3. Grid-sensitivity analysis comparing streamwise, $U_{x}$, and vertical, $U_{y}$, wind velocity components on three different grids along a) line 1 and b) line 2 upstream of the building in the centerplane. 
a)
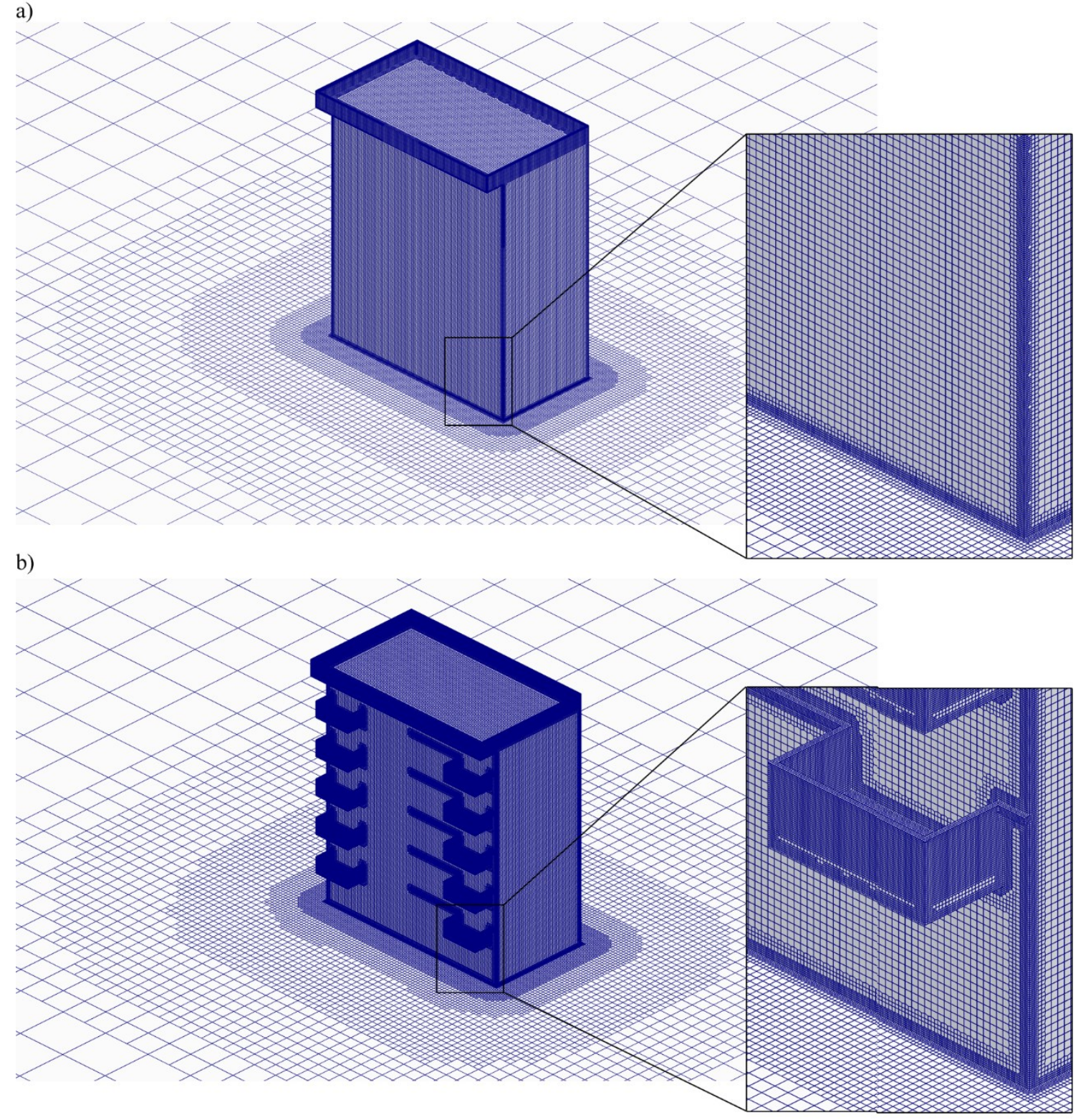

Fig. 4. Computational grids on building and part of the ground surfaces a) for parametric study (2 331855 cells) and b) facade details study (3 679975 cells). 
a)

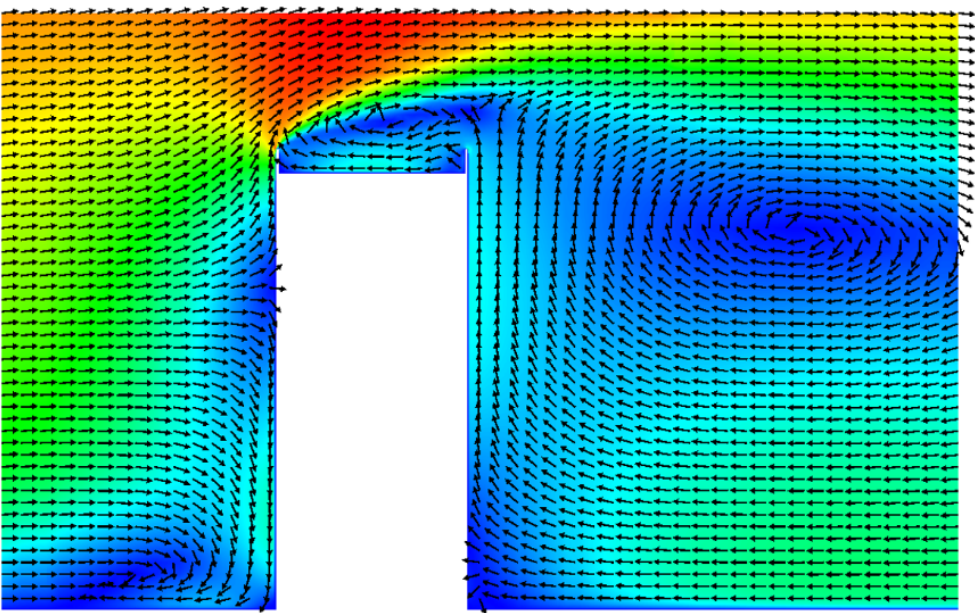

b)

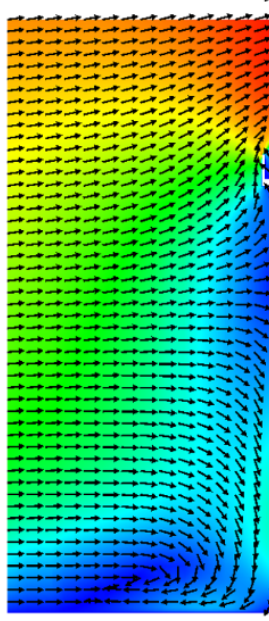

c)

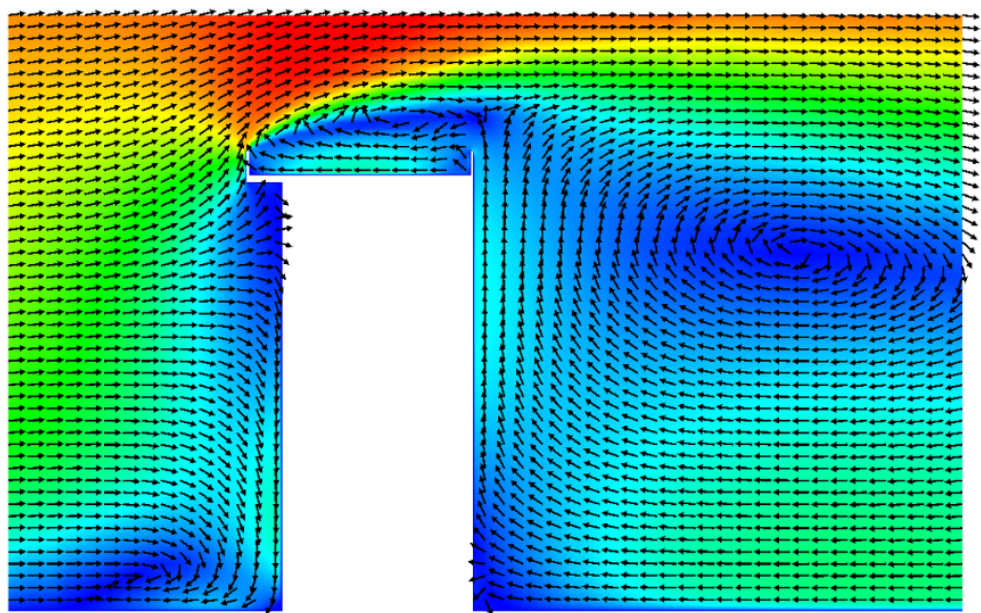

$$
U / U_{10}[-]
$$

${ }^{1.2}$

0.8

言 0.6

春 0.4

0.2

E.0

Fig. 5. Velocity vectors and contours of mean wind speed in the vertical centerplane for a) case 1 with roof-overhang length $\mathrm{L}=0 \mathrm{~m}, \mathrm{~b}$ ) case 2 with $\mathrm{L}=0.75 \mathrm{~m}$ and c) case 3 with $\mathrm{L}=1.50 \mathrm{~m}$. 
a)

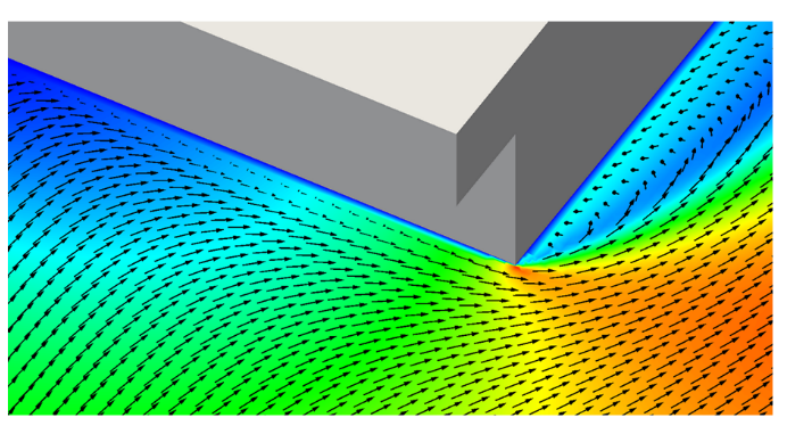

b)

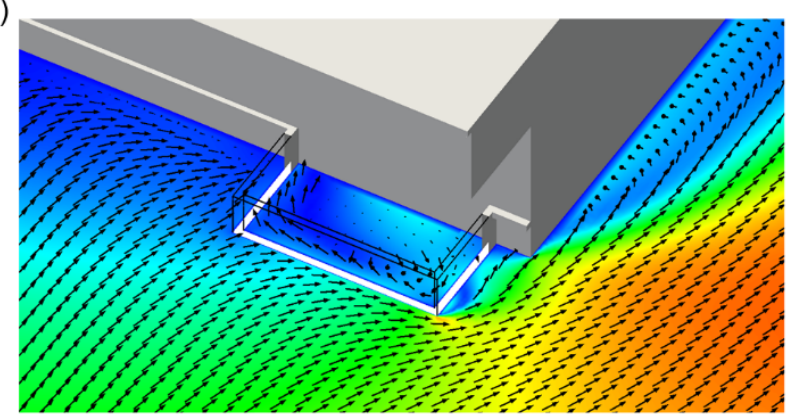

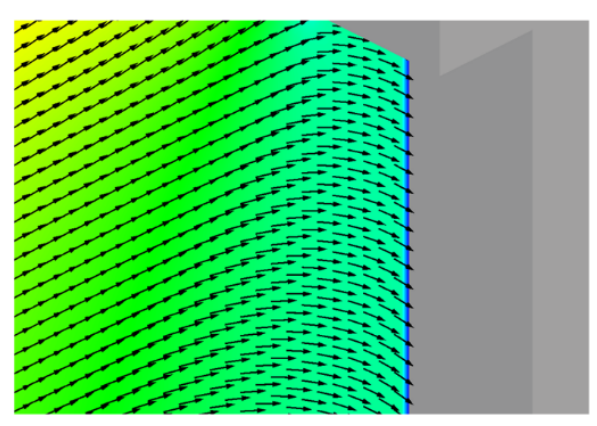

$U / U_{10}[-]$
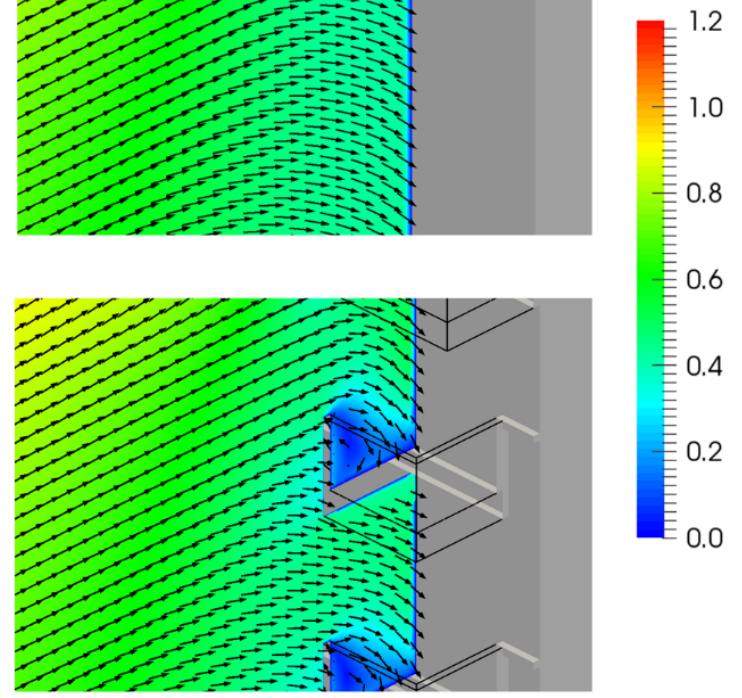

Fig. 6. Velocity vectors and contours of mean wind speed around the top floor in the horizontal and vertical centerplanes of the balcony position for a) case 3 with roof-overhang length $L=1.50 \mathrm{~m}$ and b) case 4 with $\mathrm{L}=1.50 \mathrm{~m}$ and facade details. 
a)

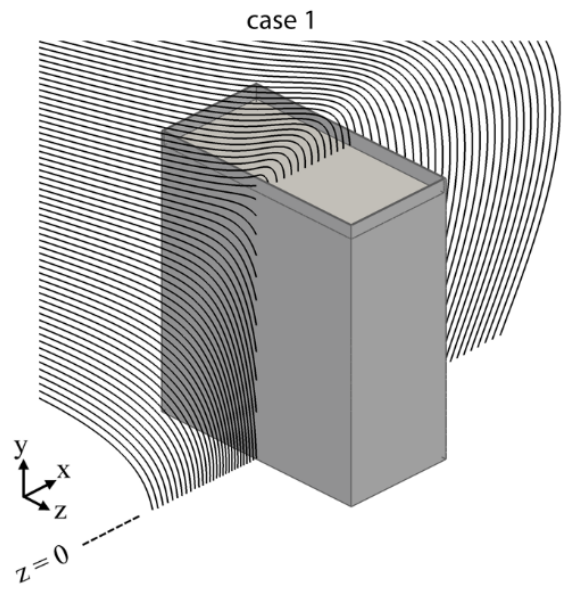

b)

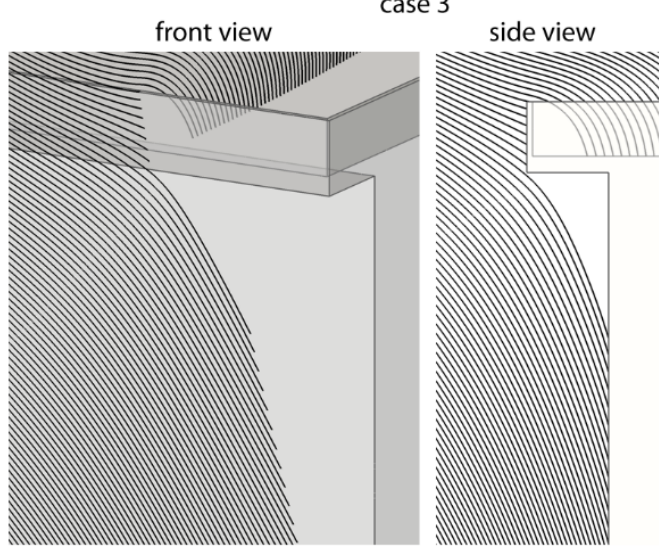

case 3
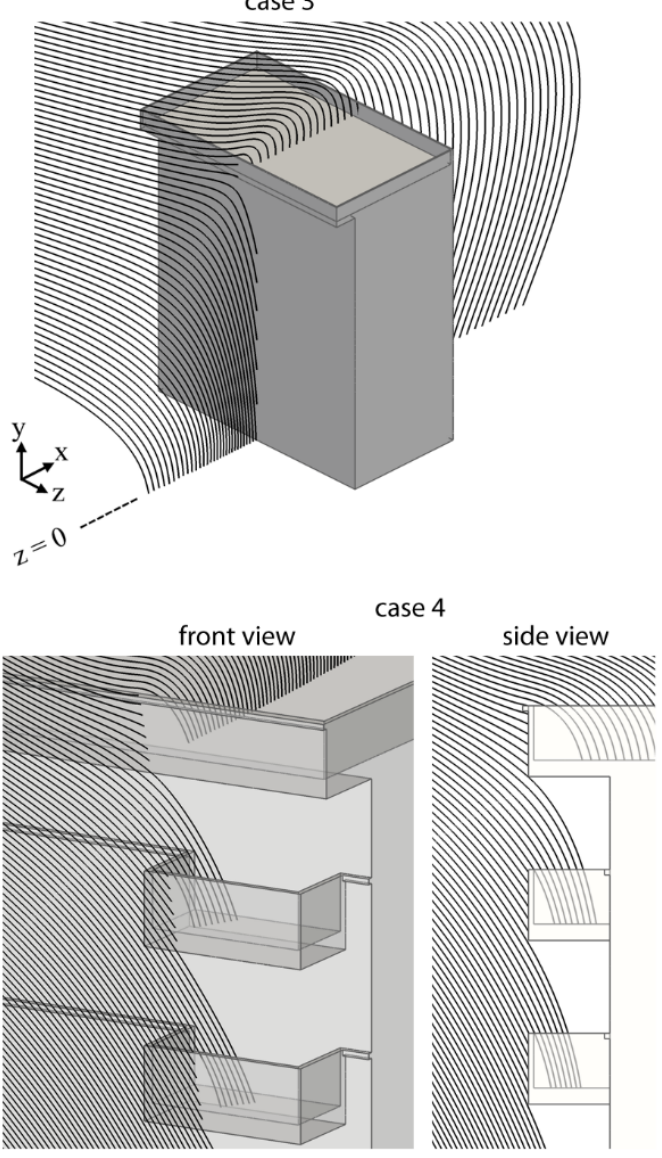

Fig. 7. Raindrop trajectories for droplet size of $1.0 \mathrm{~mm}$ in vertical planes $\mathrm{z}=0$ and $3.5 \mathrm{~m}$ for reference wind speed $U_{10}=5 \mathrm{~m} / \mathrm{s}$ for a) case 3 with roof-overhang length $\mathrm{L}=1.50 \mathrm{~m}$ and $\mathrm{b}$ ) case 4 with $\mathrm{L}=1.50 \mathrm{~m}$ and facade details.
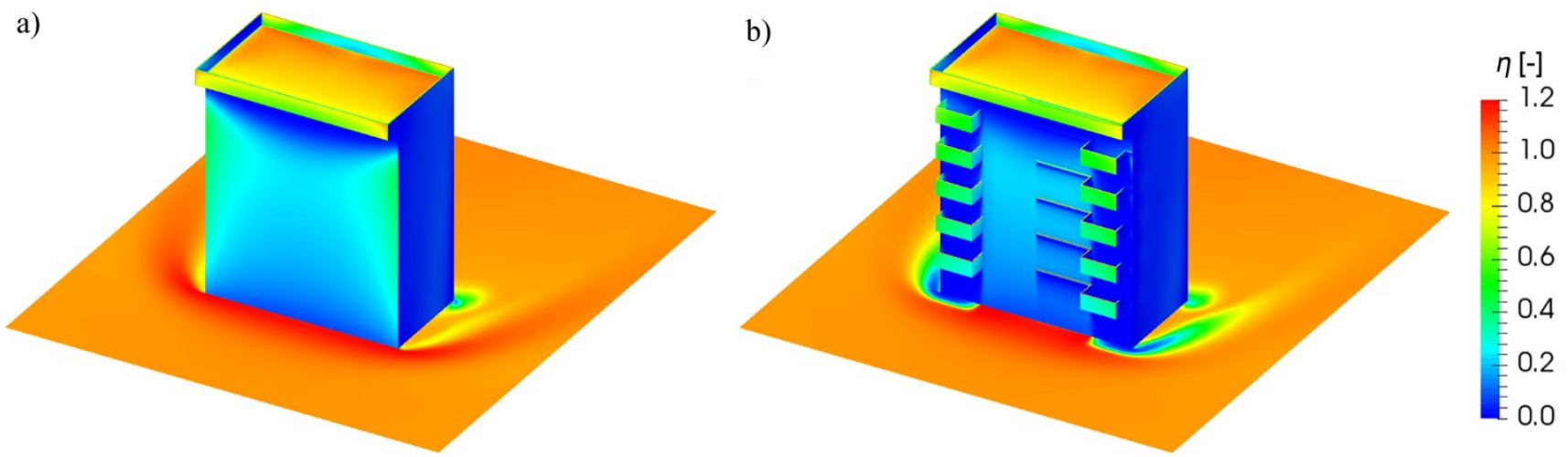

Fig. 8. Contours of catch ratio on the buildings and ground for wind speed $U_{10}=5 \mathrm{~m} / \mathrm{s}$ and rainfall intensity $R_{\mathrm{h}}=1 \mathrm{~mm} / \mathrm{h}$ for a) case 3 with roof-overhang length $\mathrm{L}=1.50 \mathrm{~m}$ and $\mathrm{b}$ ) case 4 with $\mathrm{L}=1.50 \mathrm{~m}$ and facade details. 

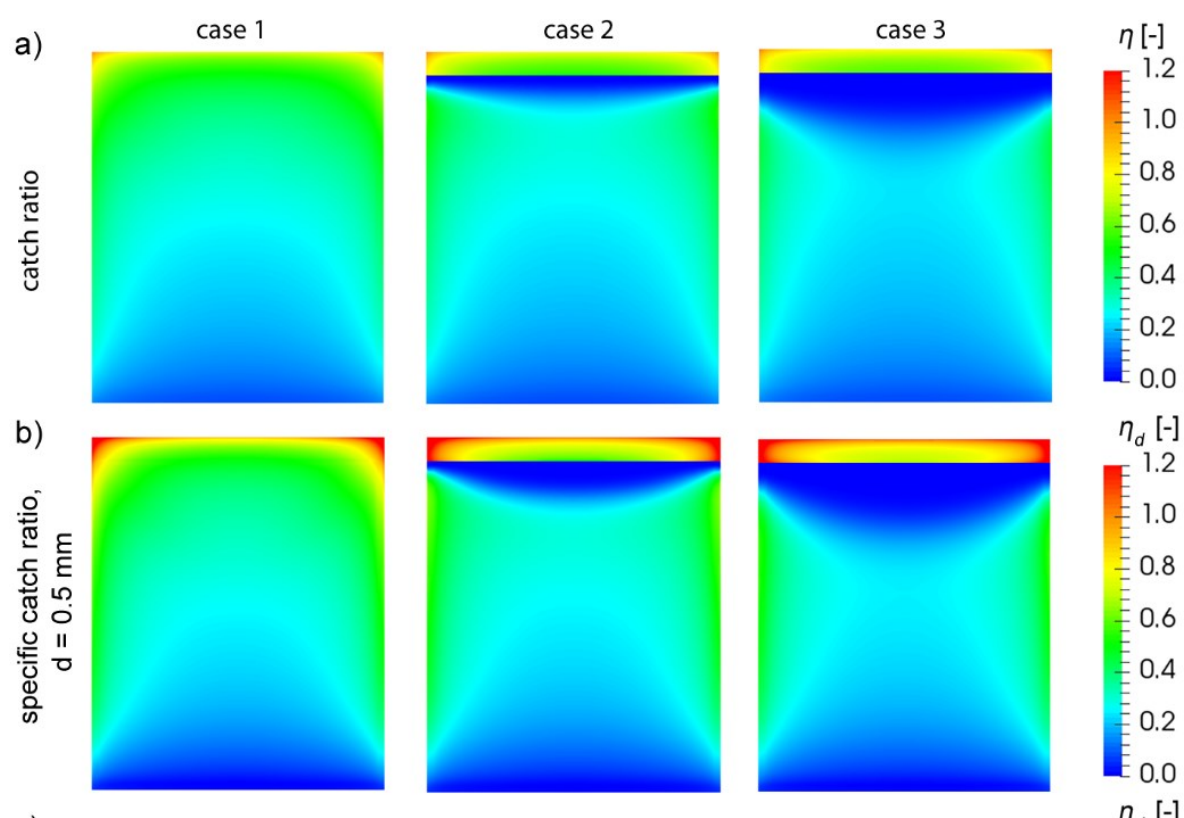

$\eta_{d}[-]$
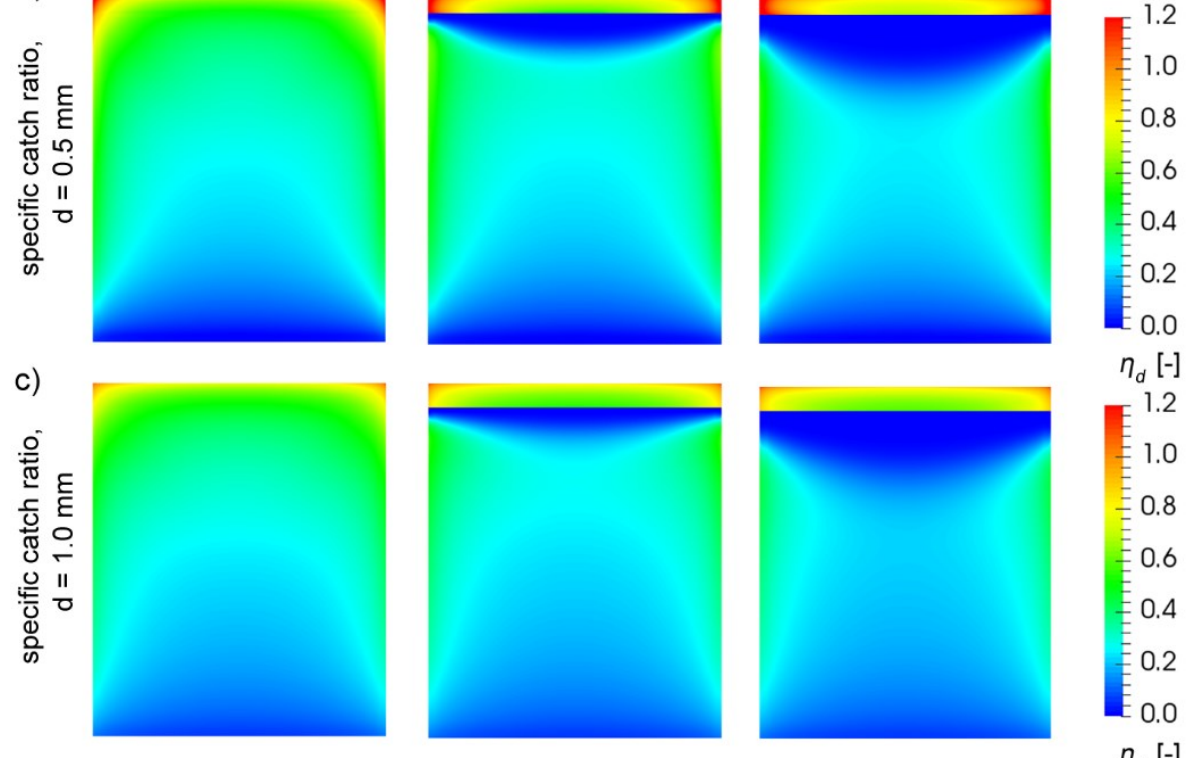

$$
\eta_{d}[-]
$$
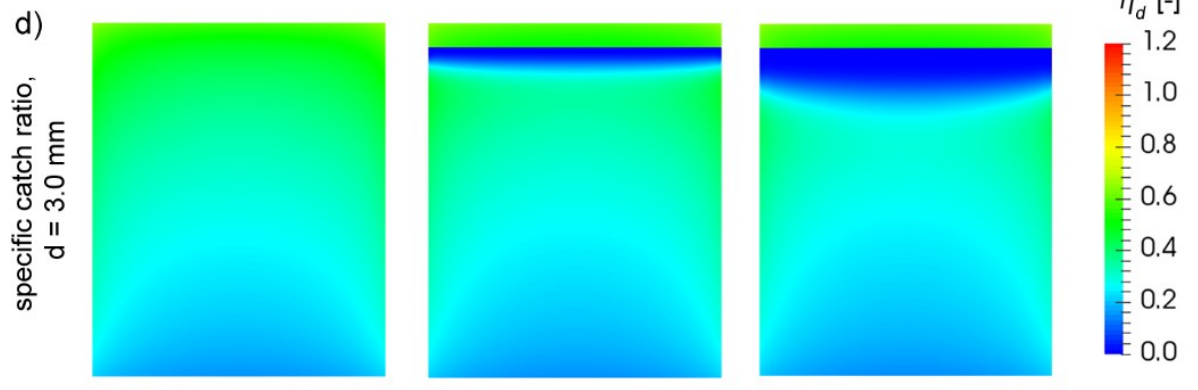

Fig. 9. Contours of a) catch ratio, $\eta$, for wind speed $U_{10}=5 \mathrm{~m} / \mathrm{s}$ and rainfall intensity $R_{h}=1 \mathrm{~mm} / \mathrm{h}$ and specific catch ratio, $\eta_{d}$, for droplet diameters of b) $0.5 \mathrm{~mm}$, c) $1.0 \mathrm{~mm}$ and d) $3.0 \mathrm{~mm}$ for wind speed $U_{10}=5 \mathrm{~m} / \mathrm{s}$ on the windward facades of a) case 1 with roof-overhang length $\mathrm{L}=0 \mathrm{~m}, \mathrm{~b}$ ) case 2 with $\mathrm{L}=0.75 \mathrm{~m}$ and c) case 3 with $\mathrm{L}=1.50 \mathrm{~m}$. 


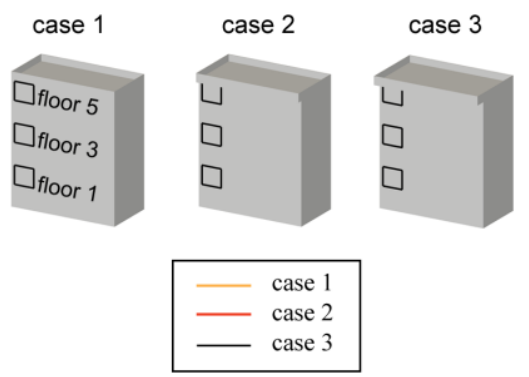

a) floor 5 :

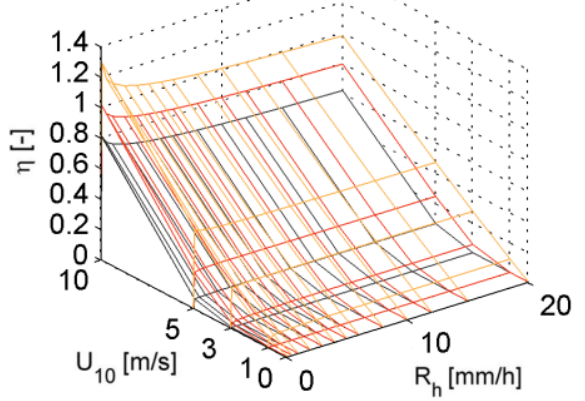

b) floor 3 :

c) floor 1 :
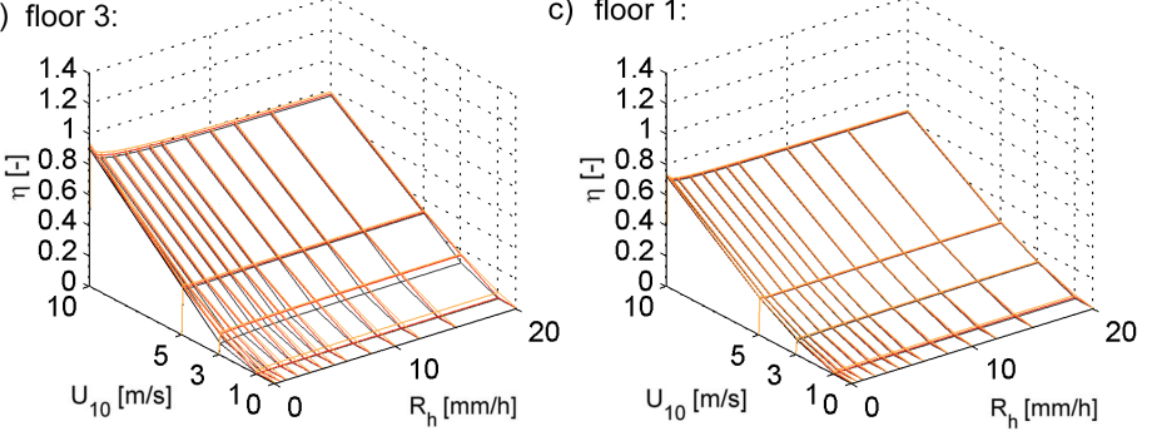

Fig. 10. Catch ratio, $\eta$, charts for case 1 with roof-overhang length $L=0 \mathrm{~m}$, case 2 with $\mathrm{L}=0.75 \mathrm{~m}$ and case 3 with $\mathrm{L}=$ $1.50 \mathrm{~m}$, surface-averaged over the indicated areas at floors a) 5, b) 3 and c) 1 .
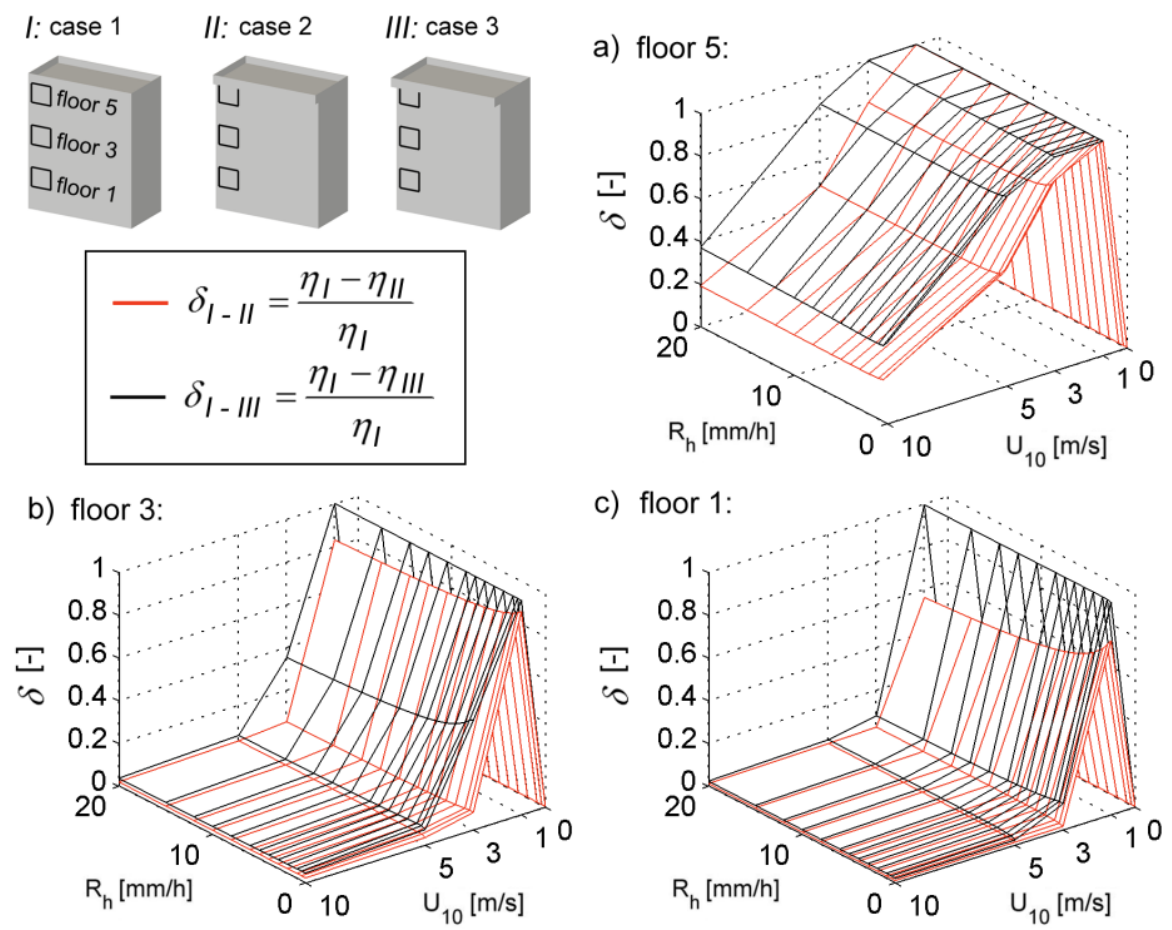

Fig. 11. Sheltering ratio, $\delta$, charts for case 2 with roof-overhang length $\mathrm{L}=0.75 \mathrm{~m}$ and case 3 with $\mathrm{L}=1.50 \mathrm{~m}$ compared to case 1 with $L=0 \mathrm{~m}$, surface-averaged over the indicated areas at floors a) 5, b) 3 and c) 1 . 
a)

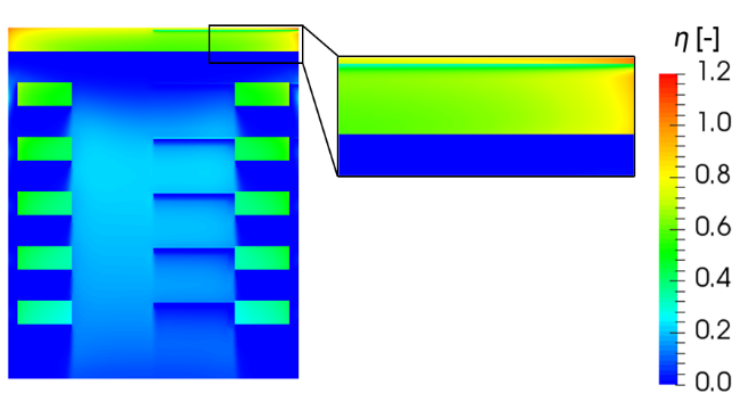

b)

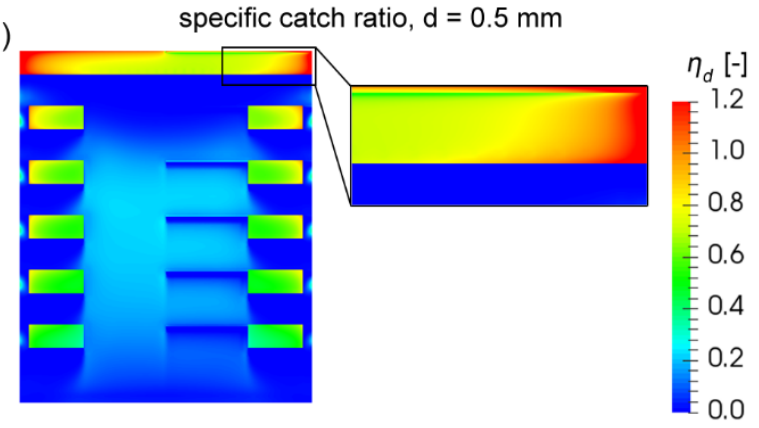

c)

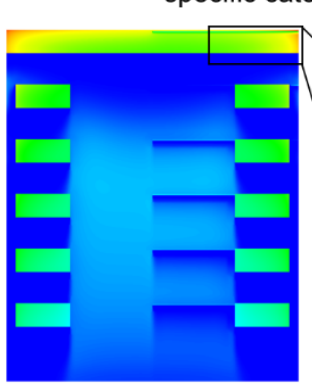

specific catch ratio, $d=1.0 \mathrm{~mm}$

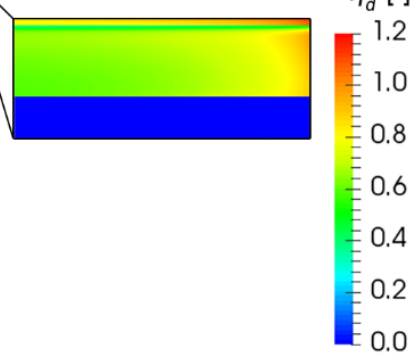

$\eta_{d}[-]$

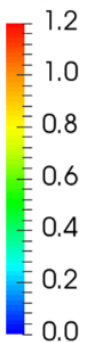

\section{2}

1.0

0.4

0.2

0.0

Fig. 12. Contours of a) catch ratio, $\eta$, for wind speed $U_{10}=5 \mathrm{~m} / \mathrm{s}$ and rainfall intensity $R_{h}=1 \mathrm{~mm} / \mathrm{h}$ and specific catch ratio, $\eta_{d}$, for droplet diameters of b) $0.5 \mathrm{~mm}$, c) $1.0 \mathrm{~mm}$ and d) $3.0 \mathrm{~mm}$ for wind speed $U_{10}=5 \mathrm{~m} / \mathrm{s}$ on the windward facade of case 4.

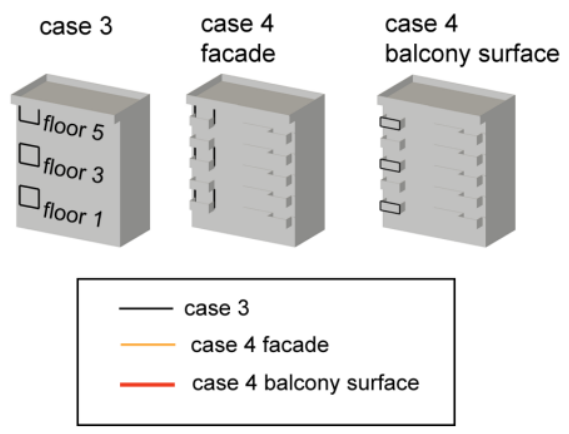

b) floor 3 :

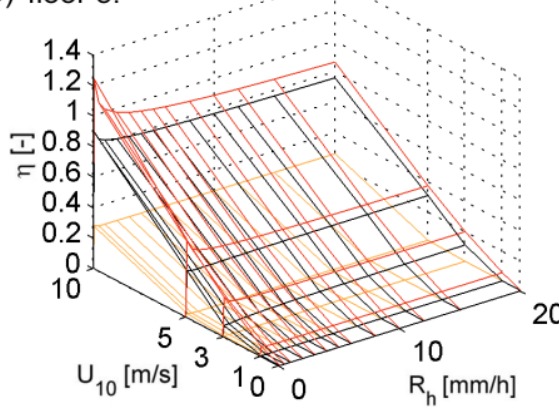

d)

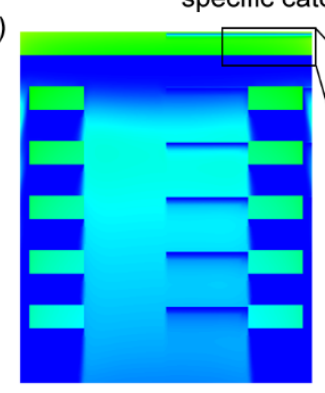

a) floor 5 :

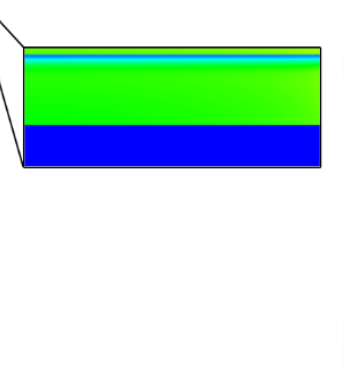




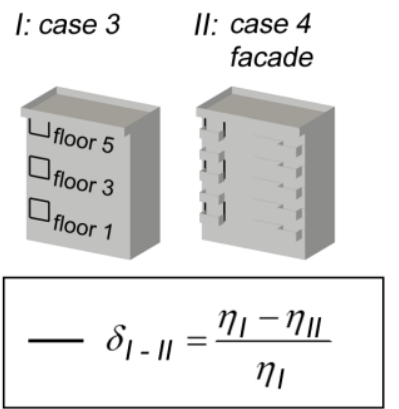

b) floor 3 :

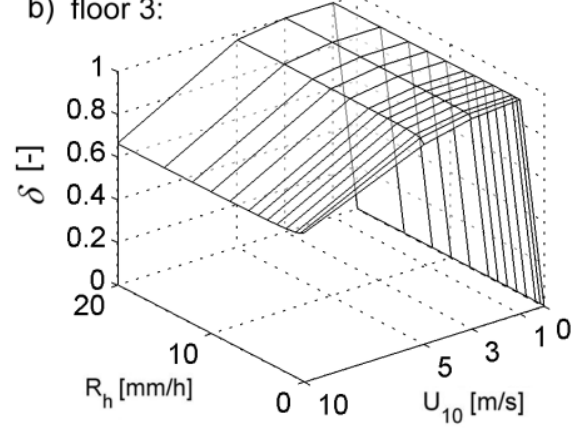

a) floor 5 :

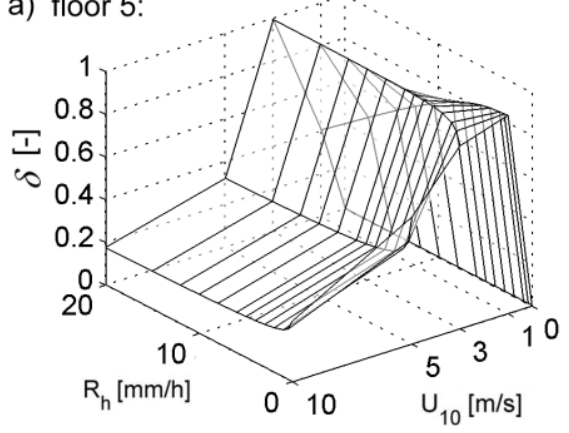

c) floor 1 :

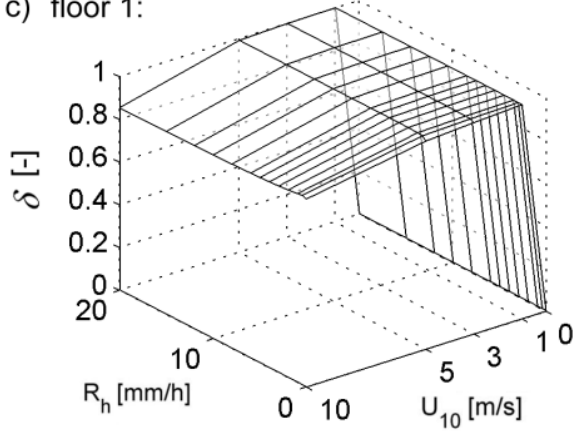

Fig. 14. Sheltering ratio, $\delta$, charts surface-averaged over the indicated areas of the facade of case 4 with roof-overhang length $\mathrm{L}=1.50 \mathrm{~m}$ and facade details compared to case 3 with $\mathrm{L}=1.50 \mathrm{~m}$ at floors a) $5, \mathrm{~b}) 3$ and c) 1 .

a)

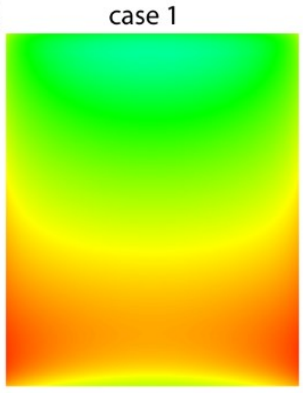

b)

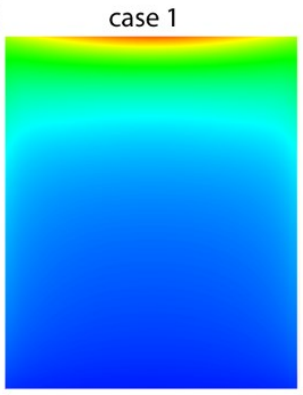

case 2

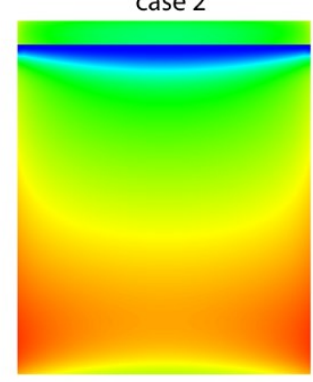

case 2

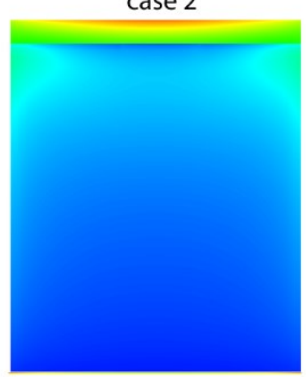

case 3

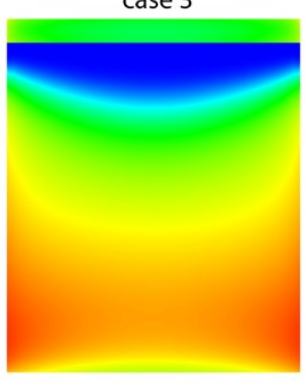

case 3

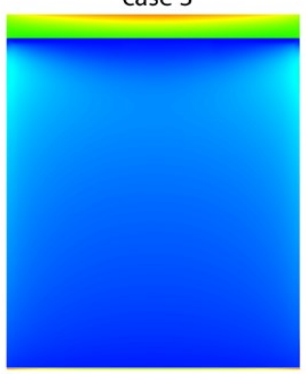

case 4
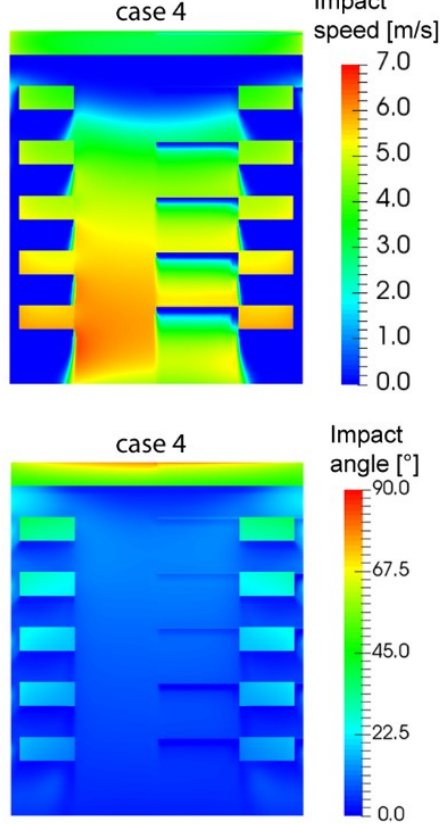

Fig. 15. Contours of a) droplet impact speed and b) droplet impact angle for raindrop size of $d=1.0 \mathrm{~mm}$ on the windward facades of different cases for wind speed of $U_{10}=5 \mathrm{~m} / \mathrm{s}$. Case 1 is with a roof-overhang length $\mathrm{L}=0 \mathrm{~m}$, case 2 with $\mathrm{L}=0.75 \mathrm{~m}$, case 3 with $\mathrm{L}=1.50 \mathrm{~m}$ and case 4 with $\mathrm{L}=1.50 \mathrm{~m}$ and facade details. Droplet impact angle indicates the angle between the droplet trajectory and the surface. 


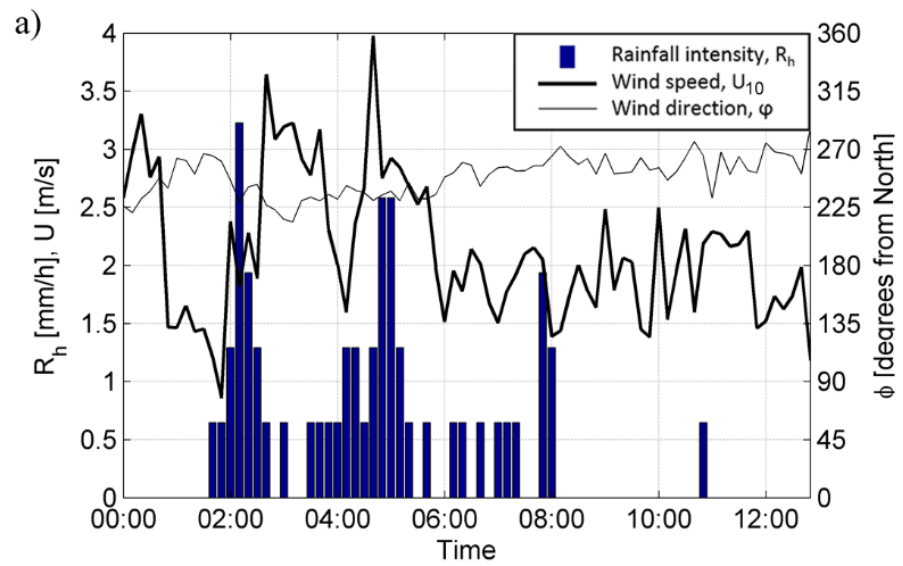

b)

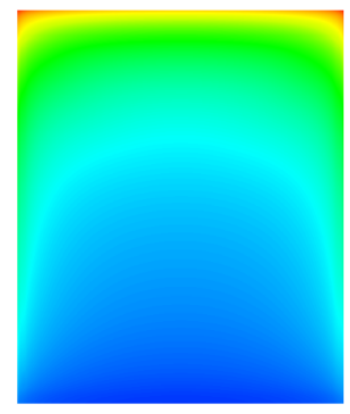

d)

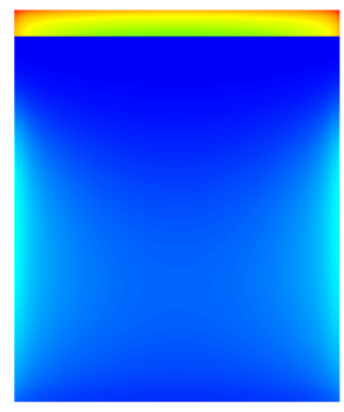

c)

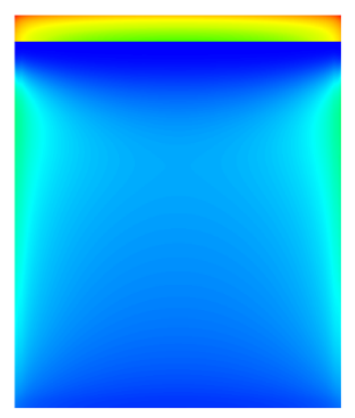

e)

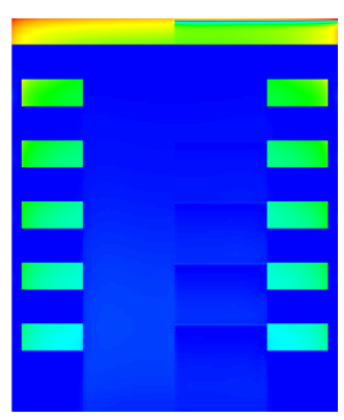

$\eta_{r e}[-]$

0.5

0.4

0.3

0.2

0.1

0.0

Fig. 16. a) Meteorological data recorded during the rain event on September 12, 2013. Contours of catch ratio at the end of the rain event on the windward facades of b) case 1 with a roof-overhang length $L=0 \mathrm{~m}, \mathrm{c}$ ) case 2 with $\mathrm{L}=0.75 \mathrm{~m}, \mathrm{~d}$ ) case 3 with $\mathrm{L}=1.50 \mathrm{~m}$ and e) case 4 with $\mathrm{L}=1.50 \mathrm{~m}$ and facade details. 